\title{
RELAP5-3D Resolution of Known Restart/Backup Issues
}

Dr. George L Mesina Nolan A Anderson

December 2014

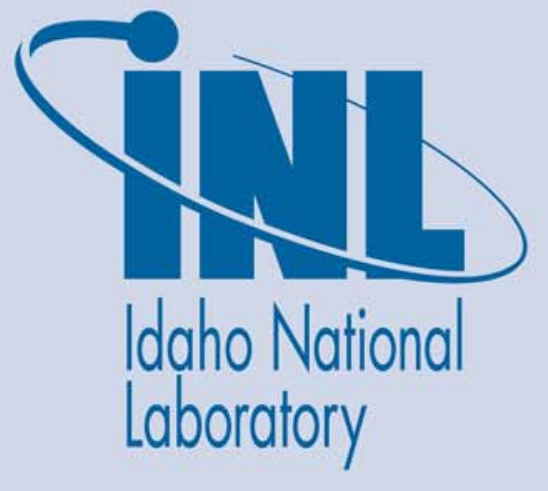

The INL is a U.S. Department of Energy National Laboratory operated by Battelle Energy Alliance 


\section{DISCLAIMER}

This information was prepared as an account of work sponsored by an agency of the U.S. Government. Neither the U.S. Government nor any agency thereof, nor any of their employees, makes any warranty, expressed or implied, or assumes any legal liability or responsibility for the accuracy, completeness, or usefulness, of any information, apparatus, product, or process disclosed, or represents that its use would not infringe privately owned rights. References herein to any specific commercial product, process, or service by trade name, trade mark, manufacturer, or otherwise, does not necessarily constitute or imply its endorsement, recommendation, or favoring by the U.S. Government or any agency thereof. The views and opinions of authors expressed herein do not necessarily state or reflect those of the U.S. Government or any agency thereof. 


\title{
RELAP5-3D Resolution of Known Restart/Backup Issues
}

\author{
Dr. George L Mesina
}

December 2014

Idaho National Laboratory Idaho Falls, Idaho 83415

http://www.inl.gov

Prepared for the

U.S. Department of Energy

Office of Nuclear Energy

Under DOE Idaho Operations Office

Contract DE-AC07-05ID14517 



\section{RELAP5-3D Resolution of Known Restart/Backup Issues}

INL/EXT-14-33685

December 2014

Heorge yesina

Dr. George besina

Staff Scientist

Nuclear System Design and Analysis Division

Reviewed by

(lithlowio

Cliff Davis

Nuclear Engineer

Nyclear Syştem Design and Analysis Division

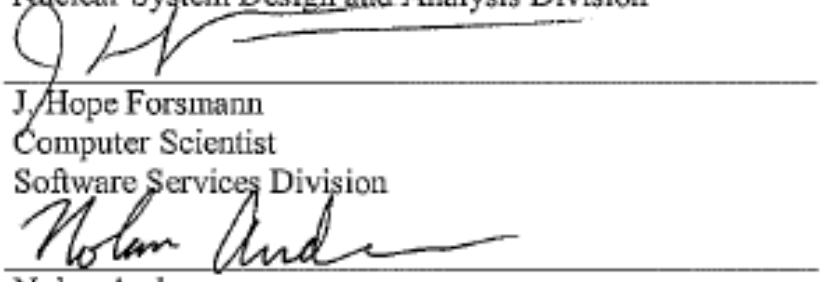

Nolan Anderson

Nuclear Engineer

Nuclear System Design and Analysis Division

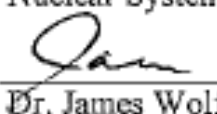

Project Manager

Nuclear System Design and Analysis Division

$$
12-\frac{8-2014}{\text { Date }}
$$

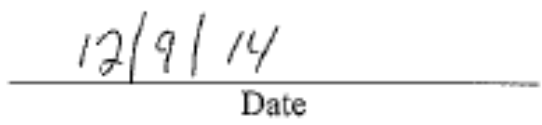

$\frac{12-9-20 / 4}{\text { Date }}$

$\frac{12-8-14}{\text { Date }}$

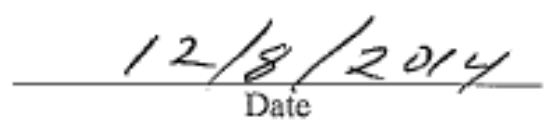





\section{EXECUTIVE SUMMARY}

The state-of-the-art nuclear reactor system safety analysis computer program developed at the Idaho National Laboratory (INL), RELAP5-3D, continues to adapt to changes in computer hardware and software and to develop to meet the ever-expanding needs of the nuclear industry. To continue at the forefront, code testing must evolve with both code and industry developments, and it must work correctly. To best ensure this, the processes of Software Verification and Validation (V\&V) are applied.

Verification compares coding against its documented algorithms and equations and compares its calculations against analytical solutions and the method of manufactured solutions. A form of this, sequential verification, checks code specifications against coding only when originally written then applies regression testing which compares code calculations between consecutive updates or versions on a set of test cases to check that the performance does not change.

A sequential verification testing system was specially constructed for RELAP5-3D to both detect errors with extreme accuracy and cover all nuclear-plant-relevant code features. Detection is provided through a "verification file" that records double precision sums of key variables. Coverage is provided by a test suite of input decks that exercise code features and capabilities necessary to model a nuclear power plant. A matrix of test features and short-running cases that exercise them is presented.

This testing system is used to test base cases (called null testing) as well as restart and backup cases. It can test RELAP5-3D performance in both standalone and coupled (through PVM to other codes) runs. Application of verification testing revealed numerous restart and backup issues in both standalone and couple modes. This document reports the resolution of these issues. 


\section{CONTENTS}

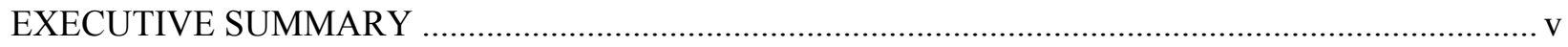

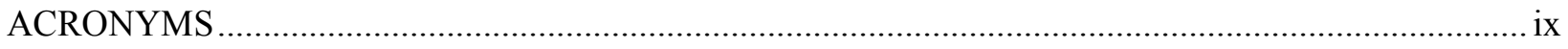

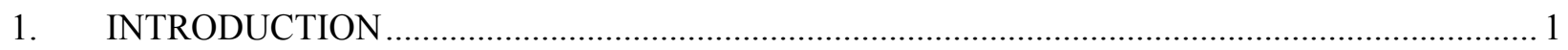

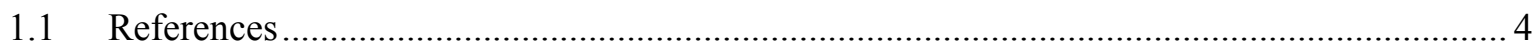

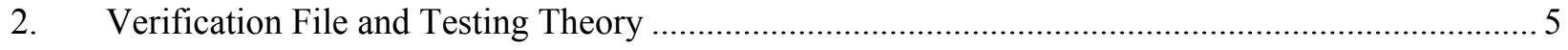

2.1 Summary of the Verification File .................................................................................. 5

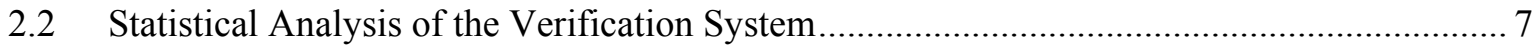

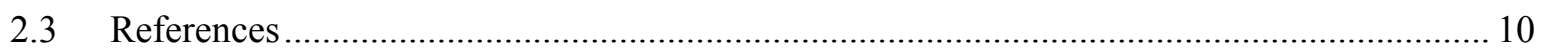

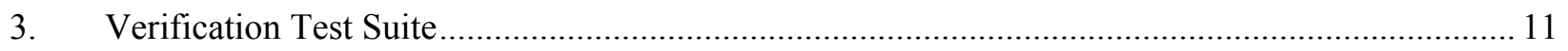

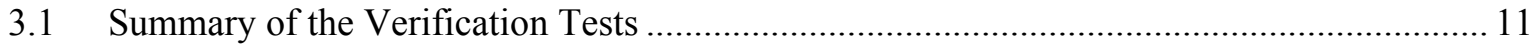

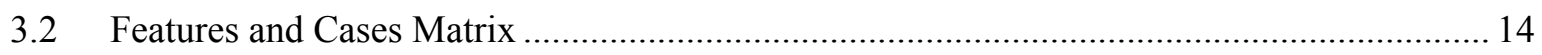

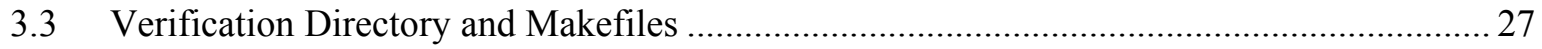

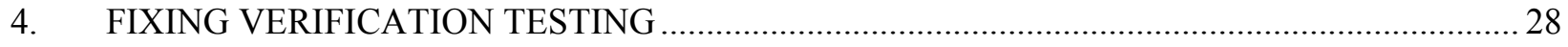

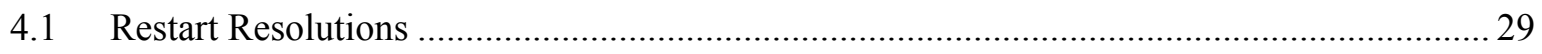

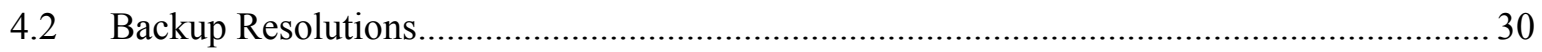

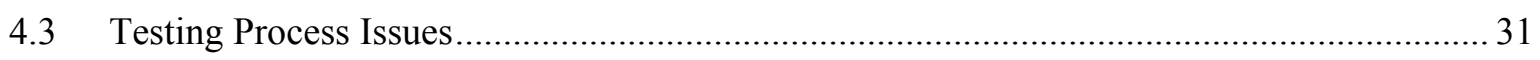

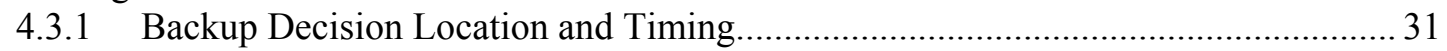

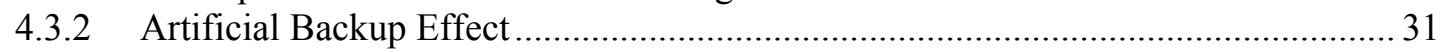

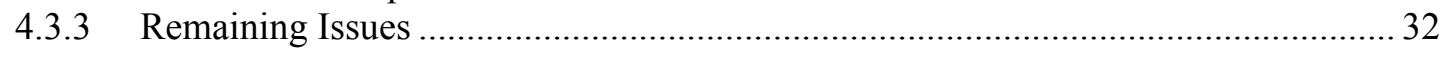

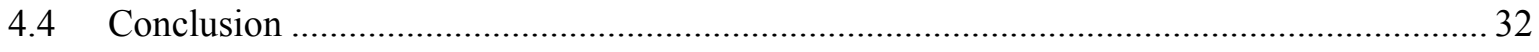

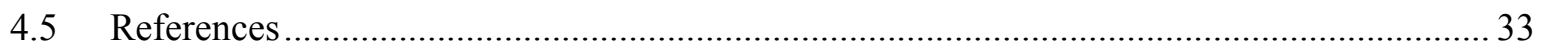




\section{TABLES}

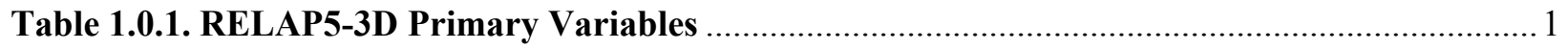

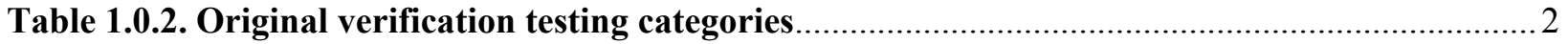

Table 1.0.3. Issues revealed by original verification testing .......................................................... 2

Table 1.0.4. Categories and modes of verification testing …........................................................... 3

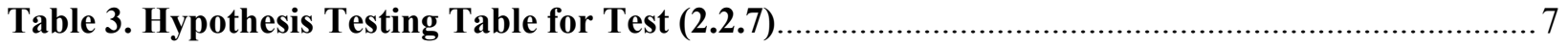

Table 3.0.1. Descriptions of new verification input file. ................................................................ 11

Table 3.2.1a. Features-Cases Matrix - Hydrodynamic Components ............................................. 15

Table 3.2.1b. Features-Cases Matrix - Hydrodynamic Components.............................................. 16

Table 3.2.2a. Features-Cases Matrix - Component Control \& Specification .................................... 17

Table 3.2.2b. Features-Cases Matrix - Component Control \& Specification .................................. 18

Table 3.2.3a. Features-Cases Matrix - Heat Transfer Specification ................................................. 19

Table 3.2.3b. Features-Cases Matrix - Heat Transfer Specification............................................. 20

Table 3.2.4a. Features-Cases Matrix - Tables and Kinetics …................................................... 21

Table 3.2.4b. Features-Cases Matrix - Tables and Kinetics …..................................................... 22

Table 3.2.6a. Features-Cases Matrix - Code Operation Control \& Misc.........................................25

Table 3.2.6b. Features-Cases Matrix - Code Operation Control \& Misc.........................................26

\section{FIGURES}

Figure 2.0.1. Verification File with 2 Cases for Edward's Pipe 6 


\section{ACRONYMS}

BC Boundary Conditions

CCFL Counter Current Flow Limiting

CHF Critical Heat Flux

CPU Central Processor Unit

DA Developmental Assessment

ECC Emergency Core Coolant

HSE Hydro Static Equilibrium

HTC Heat Transfer Coefficient

ICONE International Conference On Nuclear Energy

IEEE Institute of Electrical and Electronics Engineers

INL Idaho National Laboratory

LOCA Loss Of Coolant Accident

NURETH NUclear Reactor Thermal Hydraulics

PVM Parallel Virtual Machine

RELAP Reactor Excursion and Leak Analysis Package

RHS Right Hand Side

STD Standard

V\&V Verification and Validation 


\section{SYMBOLS}

\section{$\underline{\text { English }}$}

di Probability of detecting differences

$\mathrm{H}_{0} \quad$ Null Hypothesis

$\mathrm{H}_{1} \quad$ Alternative Hypothesis

$\mathrm{N} \quad$ Number of test cases

P Probability function

S Size of the verification file

$t_{i} \quad$ Number of timesteps if the $i^{\text {th }}$ input case

T Temperature

$\mathrm{T}_{\mathrm{r}} \quad$ Trip

UP User-reported Problem

$\mathrm{u}_{\mathrm{f}} \quad$ Liquid internal energy

$\mathrm{u}_{\mathrm{g}} \quad$ Gas internal energy

$\mathrm{V}_{\mathrm{f}} \quad$ Velocity of the Liquid (Fluid)

$\mathrm{V}_{\mathrm{g}} \quad$ Velocity of the Gas

X Random Variable for the Hypothesis Test that two runs are identical

$X_{\mathrm{a}} \quad$ Noncondensable Quality

$\mathrm{X}_{\mathrm{i}} \quad$ Random Variable for Test Case $\mathrm{i}$, the $\mathrm{i}^{\text {th }}$ input deck.

Y Control Variable

3D Three dimensional

\section{Greek}

$\alpha_{\mathrm{g}} \quad$ Void fraction of gas

$\beta \quad$ Probability of committing Type II error in a hypothesis test

$\Delta \mathrm{p} \quad$ Pressure Drop

$\Delta \mathrm{t} \quad$ Timestep for Hydrodynamic Advancement

$\Delta t_{\text {kin }} \quad$ Timestep for Neutron Kinetics Advancement

$\varepsilon \quad$ Sum of RELAP5-3d estimate errors

$\varphi \quad$ Neutron Flux

$\boldsymbol{\rho}_{\mathrm{b}} \quad$ Density of Boron 


\section{INTRODUCTION}

The state-of-the-art nuclear reactor system safety analysis computer program developed at the Idaho National Laboratory (INL), RELAP5-3D ${ }^{1-1}$, continues to adapt to changes in computer hardware and software and develops to meet the ever-expanding needs of the nuclear industry. In order to continue at the forefront, code testing must evolve with both code and industry developments, and it must work correctly. To best ensure this, the processes of Verification and Validation (V\&V), defined in IEEE-STD$610^{1-2}$, are applied. Validation is the process of evaluating a system or component (software) during or at the end of the development process to determine whether it satisfies specified requirements, i.e. will fulfill its intended use. Verification evaluates a system or component (software) to determine whether the products of a given development phase satisfy the conditions imposed at the start of that phase.

A special form of validation testing called Developmental Assessment ${ }^{1-3}$ is performed on each new RELAP5-3D release. Verification compares coding against its documented algorithms and equations and compares its calculations against analytical solutions and the method of manufactured solutions. A form of this, sequential verification ${ }^{1-4}$, checks code specifications against coding only when originally written then applies regression testing ${ }^{1-5}$ which compares code calculations between consecutive updates or versions on a set of test cases to check that the performance does not change.

Small initially, the test set grew as new features and test cases for them were added. As it grew, the $\underline{\text { diffem }}^{1-6,1-7}$ utility was developed to automate the checking process and introduce greater fidelity than visual inspection. Diffem compares the output files from two different RELAP5-3D versions, characterby-character, for each input file in the test set. Thus every difference recorded on the printed output files is detected automatically. However because output file are accurate only to five or more decimal places, this proved insufficient to guarantee the calculations were sufficiently exact when applied to complex models or long-running transients. Therefore enhancements were developed systematically.

Code features relevant to nuclear power plant modeling were identified. RELAP5-3D has numerous features to verify including phenomenological capabilities for thermal fluids trips, controls, heat transfer and neutronics. Additional code features include alternate fluids, general tables, linear equation solvers, time advancement models, special models and correlations, etc. Though these can be employed to model physical systems in a variety of application areas, the original purpose for the verification test suite was to verify RELAP5-3D code for nuclear power plant safety applications. These are listed in Table 1.0.1. The input tests for the verification suite were select to test nuclear-related code features.

Table 1.0.1. RELAP5-3D Primary Variables

\begin{tabular}{|l|l|l|}
\hline Quantity & $\begin{array}{l}\text { In } \\
\text { manual }\end{array}$ & On file \\
\hline Pressure & $\mathrm{p}$ & $\mathrm{P}$ \\
\hline Liquid internal energy & $\mathrm{u}_{\mathrm{f}}$ & $\mathrm{Uf}$ \\
\hline Gas internal energy & $\mathrm{u}_{\mathrm{g}}$ & $\mathrm{Ug}$ \\
\hline Void fraction of gas & $\alpha_{\mathrm{g}}$ & VOIDg \\
\hline Noncondensable quality & $\mathrm{X}_{\mathrm{a}}$ & QUALa \\
\hline Density of boron & $\boldsymbol{\rho}_{\mathrm{b}}$ & Boron \\
\hline Liquid velocity & $\mathrm{V}_{\mathrm{f}}$ & Vf \\
\hline Gas velocity & $\mathrm{V}_{\mathrm{g}}$ & Vg \\
\hline Heat Structure Temperature & $\mathrm{T}$ & Temp \\
\hline Neutron flux & $\varphi$ & Flux \\
\hline Timesteps sum & $\Delta \mathrm{t}, \Delta \mathrm{t}_{\text {kin }}$ & dtsum \\
\hline Trips & $\mathrm{T}_{\mathrm{r}}$ & Trips \\
\hline Control system value & $\mathrm{Y}$ & Cntrl \\
\hline
\end{tabular}


To improve the accuracy of comparisons, a verification file replaces the RELAP5-3D output file for comparisons. Arrays of primary variables listed in Table 1.0.1 along with some other important quantities are summed and recorded on the file to reduce its size. Verification files of two runs that should produce exactly the same calculations can be compared. If no differences occur for any pair of comparisons in the test suite, the code is sequentially verified. If not, the reason must be found. If it is a code bug, it must be fixed before continuing. If it is justifiable for reasons such as expected improvements due to bug fixes, model enhancements, or changes to the operating system, the code is considered to be sequentially verified.

The new verification process was designed to provide the ability to verify more code capabilities and modes of operation than simple regression testing allows. Null testing compares pairs of runs of the same input deck on two different versions or updates of RELAP5-3D. Process testing compares verification files made with the same RELAP5-3D version run on related input for which the calculations ought to be exactly the same. Related runs include comparisons of a base case run of an input model against a restart run, a run with forced backups, or one where the model is the result of multiple input cases that result in the exact same model.

The original form of Verification Testing went into RELAP5-3D version 4.1.3. It had only the first three categories of testing: null, restart, and backup as shown in Table 1.0.2.

Table 1.0.2. Original verification testing categories

\begin{tabular}{|l|l|l|}
\hline No. & Category & Description \\
\hline 1 & Null testing & Check that two code versions produce the same calculations \\
\hline 2 & Restart testing & Check that a restarted run produces the same calculations as the original run \\
\hline 3 & Backup testing & Check that the code still produces the same calculations with a forced backup \\
\hline
\end{tabular}

When verification testing was first introduced, many issues were discovered. The identified nuclearrelated code features were tested by 43 input decks with 125 input cases among them ${ }^{1-6,1-7}$. A test deck is considered to fail if there are any differences between two corresponding verification files. This can be broken down further. Verification files make individual dumps on user specified timesteps and dumps within the file are separated by the cases of the input deck whenever the deck has multiple cases. Individual cases within a given verification file may compare perfectly while others have differences. Table 1.0.3 summarizes the failures to compare perfectly, both by input deck in column 2 and by input case in column 3, for RELAP5-3D version 4.3.1.

Table 1.0.3. Issues revealed by original verification testing

\begin{tabular}{|l|c|c|}
\hline Version 4.1.3 & Failures in 43 Test Problems & Failures in 125 cases \\
\hline Null Testing & $6 / 43$ & $6 / 125$ \\
\hline Restart Testing & $25 / 43$ & $52 / 125$ \\
\hline Backup Testing & $37 / 43$ & $62 / 125$ \\
\hline
\end{tabular}

The purpose of this report is to document the improvements made to RELAP5-3D to make all the verification test suite problems run perfectly. Thus whenever pairs of corresponding verification files are 
compared for version 4.3.1, there are no differences. In the case of null testing, this means 4.3 .1 compares perfectly with 4.3.0.

A second purpose of this project is to increase the scope of verification testing. Originally, RELAP5$3 \mathrm{D}$ was verified for standalone operation only. This project adds two additional modes of operation. It is also noted that a fourth category of verification testing, multi-case verification, was developed in response to a User Problem. However, since it was not part of this project, it will not be reported in detail.

RELAP5-3D can be run standalone or as a thread or instance under the direction of the PVM (Parallel Virtual Machine) Executive. An instance of RELAP5-3D can run alone under Executive control or coupled with another thread running another code. The latter mode allows RELAP5-3D to communicate with one or more other codes to solve a complex problem that has been split via domain decomposition into pieces that are assigned to the code best-suited to modeling its apportioned part of the problem. As of version 4.3.1, only PVM coupled verification is performed. Moreover in PVM coupled mode, only null and restart testing is performed, as shown in Table 1.0.4.

Table 1.0.4. Categories and modes of verification testing

\begin{tabular}{|c|l|c|c|}
\hline $\begin{array}{l}\text { Category } \\
\text { Number }\end{array}$ & $\begin{array}{l}\text { Category } \\
\text { Name }\end{array}$ & $\begin{array}{l}\text { Standalone } \\
\text { RELAP5-3D }\end{array}$ & $\begin{array}{l}\text { RELAP5-3D Coupled } \\
\text { to RELAP-3D via } \\
\text { PVM Executive }\end{array}$ \\
\hline 1 & Null & $\mathrm{X}$ & $\mathrm{X}$ \\
\hline 2 & Restart & $\mathrm{X}$ & $\mathrm{X}$ \\
\hline 3 & Backup & $\mathrm{X}$ & $\mathrm{N} / \mathrm{A}$ \\
\hline 4 & Multi-case & INL only & N/A \\
\hline
\end{tabular}

The Section 2 details the verification file and covers the theory of verification testing. Section 3 covers the input decks that were added to test suite to make the verification test more powerful. Section 5 introduces and explains the new modes of testing. Section 6 is coding and scripting for the test. Section 7 is a Bibliography. 


\subsection{References}

1-1 The RELAP5-3D Code Development Team, "RELAP5-3D Code Manual Volume I: Code Structure, System Models and Solution Methods," INL-EXT-98-00834-V1, Revision 4.2, June, 2012.

1-2 IEEE Computer Society Standards Coordinating Committee, IEEE Standard Computer Dictionary, A Compilation of IEEE Standard Computer Glossaries 610, Library of Congress Catalog Number 90086306, ISBN 1-55937-079-3, The Institute of Electrical and Electronics Engineers, 345 East 47th Street, New York, NY 10017, USA, 1990.

1-3 The RELAP5-3D Code Development Team, "RELAP5-3D Code Manual Volume III: Developmental Assessment," INL-EXT-98-00834-V1, Revision 4.0, Section 8.2, p 8-4, June, 2012.

1-4 D. L. Aumiller, G. W. Swartele, J. W. Lane, F. X. Buschman and M. J. Meholic, "Development of Verification Testing Capabilities for Safety Codes," The $15^{\text {th }}$ International Topical Meeting on Nuclear Reactor Thermal - Hydraulics, NURETH-15, NURETH15-145, Pisa, Italy, May 12-17, 2013.

1-5 J. Watkins, Testing IT: An Off-the-Shelf Software Testing Process Handbook, ISBN: 052179546X 9780521795463, Cambridge; New York: Cambridge University Press, 2001.

1-6 G. L. Mesina, "RELAP5-3D Restart and Backup Verification Testing,” INL-EXT-13-29568, September, 2013.

1-7 G. L. Mesina, D. L. Aumiller, F. X. Buschman, “Automated, Highly Accurate Verification of RELAP5-3D," ICONE22-31153, Proceedings of the 22nd International Conference on Nuclear Engineering, Prague, Czech Republic, July 7-11, 2014. 


\section{Verification File and Testing Theory}

The verification method first released version in RELAP5-3D/4.1.3 has been expanded in three ways: form of the verification file, size of the test suite, and uses of the verification test. However, the method is still built from the same design concepts. Section 2.1 details the file and its changes. Section 2.2 advances the theory. Additions to the suite are covered in Section 3.

\subsection{Summary of the Verification File}

Software verification testing has two important aspects:

- detection - finding errors in the coding tested

- coverage - percentage of coding exercised by the test set

The first requires the test to have a high probability of detecting differences in the calculations of two different code versions for a given test case. Coverage requires development of test cases that exercise as much of the code as possible for evaluation.

The verification file was designed to be small, require little maintenance, and detect small changes in code calculations. This is accomplished by recording the sums of primary variables. There are three major categories of data/variables:

1. Primary variables from the five physical phenomena: heat transfer, thermal hydraulics, neutronics, controls and trips are listed in Table 1.0.1. The independent variable time is also primary.

2. Secondary variables derived from primary variables and used in constructing the set of equations solved for the primary variables on the next advancement. E.G. heat capacity, enthalpy, and power.

3. Output-only variables do not feed back into primary or secondary variables. E.G. water packer count.

If a primary variable differs between two code runs, variables in category 2 and 3 that are derived from it will also differ. If a secondary variable differs on a given time step, on the next step it will affect the equations of (at least) one primary variable and thus its value when the equation is solved. The sums of primary variables are also sufficient to catch some output-only variable differences that are not caused by errors in calculating those quantities. However, differences in output-only variables do not affect category 1 or 2 variables. Therefore errors created in output-only variables that are not written on the verification file go undetected by the verification test

The verification file is a versatile tool for comparing the calculations of two RELAP5-3D runs on the input files of the test suite. It provides a basis for comparison of code modeling capabilities, processes such as restart and backup, and modes of operation such as standalone mode and coupled to another code.

Shown in Figure 2.0.1, the major features of the verification file can be seen. The top or header of the file displays the computer program, version and time the executable was created, the machine on which it was run, and the date and time of the run. The footer gives the CPU time and size of the verification file. Everything in-between is the body of the verification file. At the highest level it is organized into inputcases since RELAP5-3D can run several cases in a single input deck. The title of the case is given. Within each case, data from a timestep is dumped onto the file headed by the dump and advancement number and cumulative time. The remainder of the dump displays the $\mathrm{L}_{1}$-norm of primary variables, and some other important sums. The floating point sums are accumulated in quadruple precision and are displayed in both hexadecimal and 1pe20.16 floating point formats. 
Figure 2.0.1. Verification File with 2 Cases for Edward's Pipe

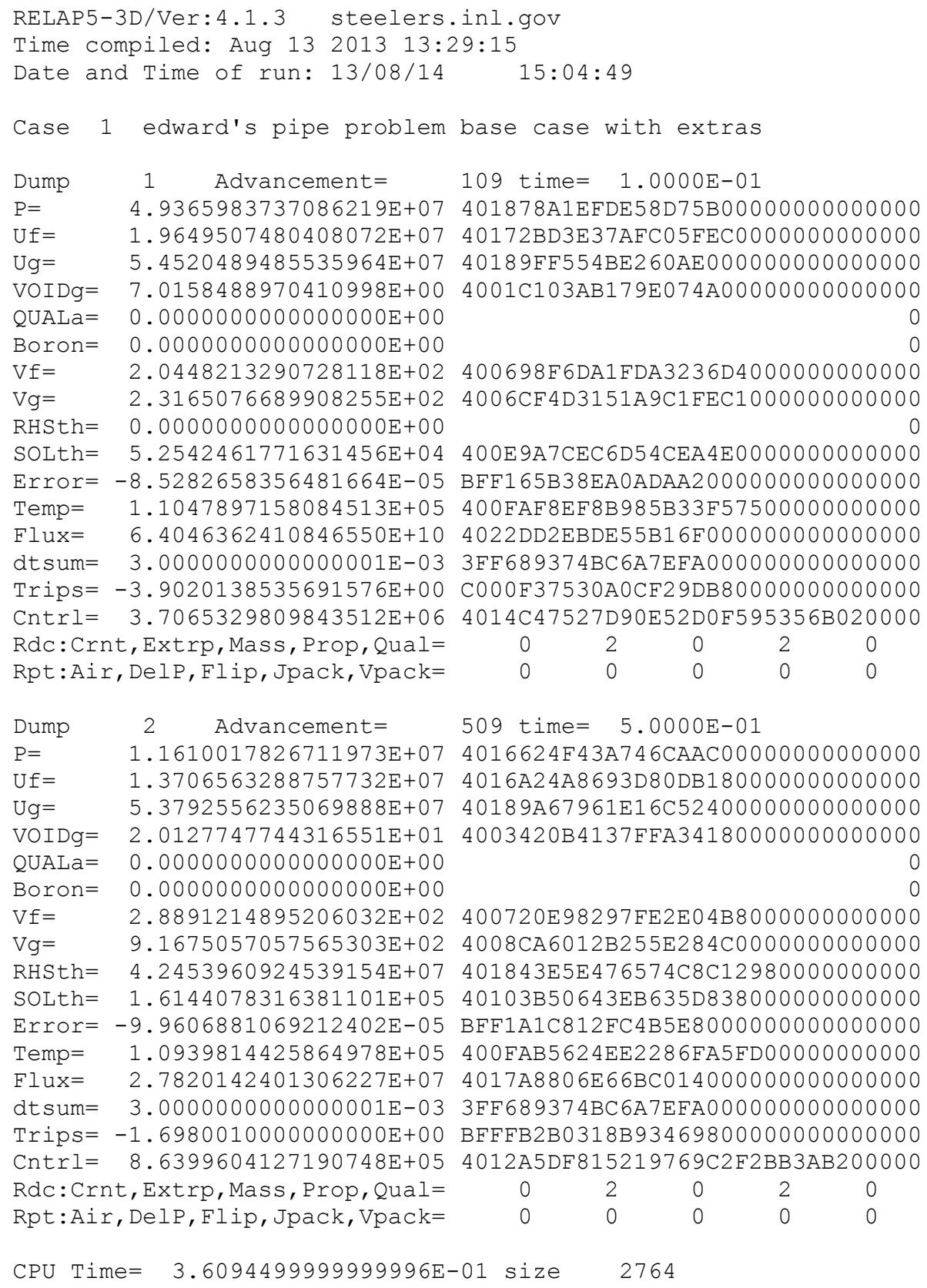

Figure 2.0.2 shows only the first dump of the new format as of RELAP5-3D/4.3.1, The decimal digits are displayed as 1pe27.20 for both time and the $\mathrm{L}_{1}$-norms. Besides formats, the new row, timesum, is the sum of both the hydrodynamic and heat transfer cumulative times. Also, the sum of time steps, dtsum, now adds the heat-transfer dt to the hydrodynamic and kinetic. An option to print the edit times is coded, but is commented out. 


\subsection{Statistical Analysis of the Verification System}

This section summarizes the statistical theory underlying the verification testing system. Theorems that were proven previously ${ }^{2-1,2-2}$ are restated without proofs. A couple new theorems are proven. This section summarizes the statistical theory underlying the verification testing system. The null and alternate hypotheses of the test are denoted $\mathrm{H}_{0}$ and $\mathrm{A}_{0}$, respectively.

$\mathrm{H}_{0, \mathrm{i}}$ : The two runs produce exactly the same calculations for test case $\mathrm{i}$.

$\mathrm{A}_{0, \mathrm{i}}$ : Code calculations are different for test case $\mathrm{i}$.

The verification test suite contains $\mathrm{N}$ test cases. The statistic used to test the hypothesis for the ith test case, $\mathrm{Xi}$, has a value of 0 if no differences are found between the two runs and 1 otherwise, and $\mathrm{X}$ is the maximum of all the Xi. Applying standard statistical methods ${ }^{[12]}$, this is expressed mathematically as:

$$
\begin{aligned}
& \mathrm{X}_{\mathrm{i}}=\left\{\begin{array}{l}
0 \text { if exactly } 0 \text { differences are found } \\
1 \quad \text { if at least one difference is found }
\end{array}\right. \\
& \mathrm{X}=\max \left\{\mathrm{X}_{\mathrm{i}} \mid \mathrm{i}=1,2, \ldots, \mathrm{N}\right\} \\
& \mathrm{H}_{0} \text { : For every test case } \mathrm{i} \text {, the two corresponding runs produce the same calculations. } \\
& \mathrm{A}_{0} \text { : Code calculations are different some test case } \mathrm{i} \text {. } \\
& \text { Verification Test: Accept the null hypothesis if } \mathrm{X}=0 \text {, but reject it when } \mathrm{X}=1 \text {. }
\end{aligned}
$$

Hypothesis testing potentially commits two kinds of errors. The first, Type I Error or false positive, is the rejection of the null hypothesis when it is true. That means finding differences when there are none. The second kind of error, called Type II Error or a false negative, is to accept the null hypothesis when it is false. That means there are differences that go undiscovered. Table 3 summarizes this.

Table 3. Hypothesis Testing Table for Test (2.2.7)

\begin{tabular}{|l|l|l|}
\hline & $\begin{array}{l}\mathbf{H}_{\mathbf{0}} \text { is true } \\
\text { No differences exist }\end{array}$ & $\begin{array}{l}\mathbf{A}_{\mathbf{0}} \text { is true } \\
\text { Differences exist }\end{array}$ \\
\hline Accept $\mathbf{H}_{\mathbf{0}}$ & $\begin{array}{l}\text { Correct } \\
\text { Report: "No differences" }\end{array}$ & $\begin{array}{l}\text { Type II Error } \\
\text { Don't find extant differences }\end{array}$ \\
\hline Reject $\mathbf{H}_{\mathbf{0}}$ & $\begin{array}{l}\text { Type I Error } \\
\text { Detect non-existent differences }\end{array}$ & $\begin{array}{l}\text { Correct } \\
\text { Report: "Differences found" }\end{array}$ \\
\hline
\end{tabular}

The probabilities of committing Type I and Type II Error are denoted $\alpha$ and $\beta$. These are all standard definitions ${ }^{2-3}$.

$$
\begin{aligned}
& \alpha=\mathrm{P}(\text { Type I Error })=\mathrm{P}\left(\text { Reject } \mathrm{H}_{0} \mid \mathrm{H}_{0} \text { is true }\right)=\text { Level of significance of the test } \\
& \beta=\mathrm{P}(\text { Type II Error })=\mathrm{P}\left(\text { Accept } \mathrm{H}_{0} \mid \mathrm{H}_{0} \text { is false }\right) \\
& \text { Power of the test }=1-\beta
\end{aligned}
$$


Some useful statements about the verification test have been proven. These show that the verification test is very powerful and reliable.

THEOREM 1: Verification Test (2.2.7) always accepts the null hypothesis when it is true.

Proof: Suppose $\mathrm{H}_{0}$ is true. Then there are no differences to detect in any test in the entire suite. Thus, for each test in the suite, $\mathrm{X}_{\mathrm{i}}=0$. Therefore, $\mathrm{X}=\max \left\{\mathrm{X}_{\mathrm{i}}\right\}=0$ always (when $\mathrm{H}_{0}$ is true). Since $\mathrm{X}$ is 0 , Test (2.2.7) accepts $\mathrm{H}_{0}$. Thus, $\mathrm{P}\left(\right.$ Accept $\mathrm{H}_{0} \mid \mathrm{H}_{0}$ is true $)=\mathrm{P}\left(\mathrm{X}=0 \mid \mathrm{H}_{0}\right.$ is true $)=1$. Q.E.D.

COROLLARY: Verification Test (2.2.7) has level of significance, $\alpha=0$.

PROOF: $\quad \alpha=\mathrm{P}\left(\mathrm{X}=1 \mid \mathrm{H}_{0}\right.$ is true $)=0$. The test commits no Type I Error. It never detects non-existent differences.

Interpretation: If properly programmed, the verification test will never report nonexistent code bugs. The next two results are proven in exactly the same way.

THEOREM 2: Restart Test (2.2.7) commits no Type I Error. It has significance level, $\alpha=0$.

THEOREM 3: Backups Test (2.2.7) commits no Type I Error. It has significance level, $\alpha=0$.

Despite these powerful results, Test (2.2.7) can commit Type II Error. It can miss actual differences. There are three potential causes:

1. On timesteps when verification dumps are not made, the calculations could be different.

2. Two arrays may differ yet have the same $\mathrm{L}_{1}$-norm.

3. $\mathrm{L}_{1}$-norms of primary variables catch the differences, but do not account for all output-only variables.

Consider the first issue. In the authors' experience, two runs do not differ on some time-steps but have identical sums on steps when verification dumps are made. For all tests in the verification suite, once the primary variables diverge even slightly, the differences do not disappear on later time advancements. A verification dump always occurs on the final step to catch differences.

Another source of Type II Error is the possibility that significant values in some primary variable array may differ, but the $\mathrm{L}_{1}$-norms are the same. For example, if velocities of two runs of the same input model were equal but opposite in sign, or if the first and second entry of a primary variable array were swapped between two runs, the $\mathrm{L}_{1}$-norms would be the same. Such solutions cannot occur for a wellposed system of equations, a RELAP5 topic discussed in many sources ${ }^{2-4}$.

The second source of Type II Error cannot be completely eliminated due to finite precision arithmetic. The next result quantifies it.

Consider the sample space of length-N arrays of double-precision numbers. Fortran uses IEEE 754 quadruple-precision floating-point format ${ }^{2-5,2-6}$, binary128. It has 1 sign bit, 15 exponent bits, and a significand (or mantissa) with 113bits (not 112 because the lead bit of the significand is always 1 implicitly, unless the whole fraction part is 0 , so the one is not stored). The total precision in decimal digits is $34.02 \approx \log _{10}\left(2^{113}\right)$. Unit round-off, for which $1.0+\varepsilon>1.0$ and $1.0+\varepsilon / 2=1.0$, is $\varepsilon=1.9 \times 10^{-34}$. In double precision, the significand has 49 bits, the exponent has 15 , and unit round-off is $\delta=2.2 \times 10^{-16}$.

Theorem 4: If (1) $\mathbf{u}$ and $\mathbf{v}$ correspond to the same primary variable from different RELAP5-3D runs (satisfy the governing equations), (2) the $\mathrm{L}_{1}$-norms are calculated in quadruple precision, (3) $\mathrm{N}>3$, then $\mathrm{P}\left(\|\mathbf{u}\|_{1}=\|\mathbf{v}\|_{1} \mid \mathbf{u} \neq \mathbf{v}\right)<10^{-18}$.

Proof: Consider two distinct double-precision arrays of length two that have the same sum. Divide by the larger value to normalize. If the sums $1.0+A_{0}=1.0+A_{1}$ while $A_{0}>A_{1}$, then $A_{0}-A_{1}<\varepsilon$. But $A_{1}$ and $\mathrm{A}_{0}$ are double-precision, so $\mathrm{A}_{0}-\mathrm{A}_{1}>\delta \mathrm{A}_{0}$, otherwise $\mathrm{A}_{1}=\mathrm{A}_{0}$. By transitivity $\varepsilon>\delta \mathrm{A}_{0}$, so $\mathrm{A}_{0}<\varepsilon / \delta=10^{-18}$.

Let the sample space be arrays of length $\mathrm{N}$ of double-precision numbers from $\varepsilon$ to 1.0. Represented as a rounded 16 decimal digit number, $A=10^{-\mathrm{m}} \times\left(\mathrm{a}_{1}, \mathrm{a}_{2} \mathrm{a}_{3} \ldots \mathrm{a}_{16}\right)$. The quadruple precision sum, $1+\mathrm{A}$, is: 


$$
\begin{array}{ll}
1.0+\mathrm{A}=1.0 \ldots 0 \mathrm{a}_{1} \ldots \mathrm{a}_{16} 0 \ldots 0 & \text { if } \mathrm{A}>10^{-18} . \\
1.0+\mathrm{A}=1.0 \ldots 0 \mathrm{a}_{1} \ldots \mathrm{a}_{16-\mathrm{k}} & \text { if } 10^{-18-\mathrm{k}}>\mathrm{A}>10^{-18-\mathrm{k}-1} .
\end{array}
$$

For $10^{-18-\mathrm{k}}>\mathrm{A}>10^{-18-\mathrm{k}-1}$, there are $10^{\mathrm{k}}$ distinct sums and $10^{16-\mathrm{k}}$ indistinct. The numbers of indistinct sums is $\mathrm{S}=\sum_{k=1}^{16} 9 \times 10^{k-1}<10^{16}$. The sample space of length $\mathrm{N}$ arrays has $(\mathrm{N}-1) \times 10^{34}$ possible sums for $\mathrm{N}>3$. The ratio of indistinct sums to possible sums is $\mathrm{S} /\left[(\mathrm{N}-1) \times 10^{34}\right]<10^{-18}$. Q. E. D.

Corollary 2: Under the same hypotheses, $\mathrm{P}(\mathrm{X}=0 \mid$ primary or secondary variables differ $)<10^{-18}$.

Output-only variables have great importance to training simulators whose alarms may be triggered by one of these variables, and to users who view the printed output files. To check these variables, the verification test can be combined with a test of output-only quantities.

The diffem ${ }^{[6,7]}$ utility performs a character by character comparison of output-only values in the printed output file. Since 5 or more decimal places are printed, the worst error committed by diffem in output-only variables is due to round-off. The error is $\mathrm{D}<0.5 \times 10^{-5}$.

The power of the combined test is considered next. Power is $1-\mathrm{P}$ (Type II Error) and relates to round-off error.

THEOREM 5: For a single test case of a well-posed problem, the combined verification test (2.2.7) and diffem test has Type II Error, $\beta<10^{-5}$.

PROOF: Two runs of the model are made, either by different code versions or to test different code processes or modes. Consider all variables in RELAP5-3D data for a given input deck on a time step for which verification data is written. $\mathrm{P}$ (Type II Error $)=\mathrm{P}(\mathrm{X}=0 \mid$ differences exist between two runs).

Let $\mathrm{A}=$ the sets of data for which primary or secondary variables differ.

Let $\mathrm{B}=$ the sets of data where Category 3 variables differ, but Category 1 and 2 variables do not.

Let $\mathrm{C}=$ the sets of data for which $\mathrm{X}=0$.

$$
\begin{aligned}
\mathrm{P} \text { (Type II Error) } & =P(C \mid(A \cup B))=\frac{P(C \cap(A \cup B))}{P(A \cup B)}=\frac{P(C \cap A \cup C \cap B)}{P(A \cup B)} \\
& =\frac{P(C \cap A)+P(C \cap B)-P(C \cap A \cap C \cap B)}{P(A \cup B)} \\
& <\frac{P(C \cap A)}{P(A \cup B)}+\frac{P(C \cap B)}{P(A \cup B)}<\frac{P(C \cap A)}{P(A)}+\frac{P(C \cap B)}{P(B)} \\
& =\mathrm{P}(\mathrm{C} \mid \mathrm{A})+\mathrm{P}(\mathrm{C} \mid \mathrm{B})<10^{-18}+0.5 \times 10^{-5}
\end{aligned}
$$

Therefore by Equation (2.2.9), $\beta<10^{-5}$. Q. E. D.

By Equation (2.2.10), the power of the combined verification (2.2.7) and diffem test is $99.999 \%$ for a single test case. This theorem means that for the features the input deck is designed to test, there is one chance in $10^{5}$ that the combined test will miss an error if it exists. However, the theorem does not address the power of the combined test to find errors in the code across the entire verification test suite. 


\subsection{References}

2-1 G. L. Mesina, "RELAP5-3D Restart and Backup Verification Testing,” INL-EXT-13-29568, September, 2013.

2-2 G. L. Mesina, D. L. Aumiller, F. X. Buschman, "Automated, Highly Accurate Verification of RELAP5-3D," ICONE22-31153, Proceedings of the 22nd International Conference on Nuclear Engineering, Prague, Czech Republic, July 7-11, 2014.

2-3 V. K Rohatgi, An Introduction to Probability Theory and Mathematical Statistics, Second Edition, ISBN-10: 0-471-34846-5, John Wiley \& Sons, Inc., NY, Oct 2000.

2-4 V. H. Ransom and V. A. Mousseau, "Convergence and Accuracy Expectations for Two-Phase Flow Simulations," Canadian Nuclear Society International Conference on Simulation Methods in Nuclear Engineering, Montreal, Canada, April 18-20, 1990.

2-5 W. Kahan "IEEE Standard 754 for Binary Floating-Point Arithmetic," Elect. Eng. \& Computer Science, Univ. of California, Berkeley CA 94720-1776, p4, October, 1997.

2-6 J. C. Adams, et al, The Fortran 2003 Handbook, The Complete Syntax, Features, and Procedures, ISBN 978-1-84628-378-9, Library of Congress 2008934286, Springer, springer.com, October 31, 2008 . 


\section{Verification Test Suite}

As stated previously, there are two fundamental aspects controlling the Type II error of Test (2.2.7), namely, the detection of differences for a given input case, enabled by the verification file, and the coverage of the program provided by the test cases of the Test suite. The second component of verification is coverage. The test suite provides coverage.

Coverage analysis typically examines the lines, functions and subprograms of a code. The verification method developed here examines features of the code instead. The features include the most commonly used features in RELAP5-3D as well as those important for modeling nuclear power plants. The suite can be expanded to include testing of more features in the future.

Section 3.1 summarizes the new verification input tests. Section 3.2 displays them in the verification test matrix.

\subsection{Summary of the Verification Tests}

The verification test suite expanded in RELAP5-3D version 4.3.1 to include 20 new sets of tests shown in Table 3.0.1. The resulting test suite has three modes of running RELAP5-3D for verification testing, namely standalone, controlled by the Executive, and coupled to another instance of itself through the Executive. In addition, a fourth categories of verification tests, the multi-test case for standalone RELAP5-3D mode, was added to resolve a user problem. Note that multi-case testing is not available in modes involving the PVM Executive because the Executive does not have multi-case capability.

Table 3.0.1. Descriptions of new verification input file.

\begin{tabular}{|c|c|}
\hline Test ID & \# Description \\
\hline 1. 2 phspump & $\begin{array}{l}12 \text { Tests two-phase pump head degradation as a function of void fraction alone and as a function of void fraction } \\
\text { and pressure. }\end{array}$ \\
\hline 2. 3dflow & 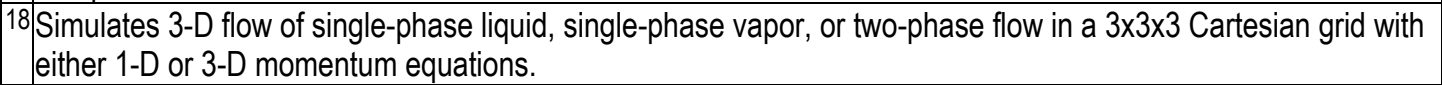 \\
\hline 3. ans & $\begin{array}{l}9 \text { Tests decay heat options with the point kinetics model, fission power types, fission product types available with } \\
\text { each ANS standard, and the G-factor contribution to the decay heat. }\end{array}$ \\
\hline 4. boronm & 4 Tracks a square wave in boron concentration through a constant area pipe with and without Godunov method. \\
\hline 5. crit & $\begin{array}{l}4 \text { Tests Ransom-Trapp and Henry-Fauske critical flow models for a range of stagnation conditions including } \\
\text { subcooled, two-phase, and superheated in a small horizontal pipe. Also tests cases with no choking allowed } \\
\text { and homogeneous flow. }\end{array}$ \\
\hline 6. cyl3 & 1 Tests the metal water reaction model for steam flowing past the right surface of a cylindrical heat structure. \\
\hline 7. duklerm & $\begin{array}{l}5 \text { Tests the CCFL model using Dukler-Smith air-water countercurrent flow data. Wallis, Kutateladze, and Bankoff } \\
\text { correlations are tested. }\end{array}$ \\
\hline 8. eccmix & 1 Models a portion of the cold leg of a typical PWR during ECC injection. \\
\hline 9. edhtrkm & $\begin{array}{l}5 \text { Edward's pipe simulates a rapid blowdown of a pipe. Includes extras: reactor kinetics, heat structure cosine } \\
\text { temperature problems, and all control variables types, but shaft. Cases use fluids: h2o, d2o, h2on, h2o95, hen, } \\
\text { and an air/water mixture. }\end{array}$ \\
\hline 10.eflag & $\begin{array}{l}2 \begin{array}{l}\text { Simulates blowdown of one vessel into another to check the effect of the e-flag on the thermodynamic state in } \\
\text { the downstream vessel. }\end{array}\end{array}$ \\
\hline 11.enclss & 1 Steady-state calculation of a graphite stack using the heat conduction enclosure model. \\
\hline 12.fric & 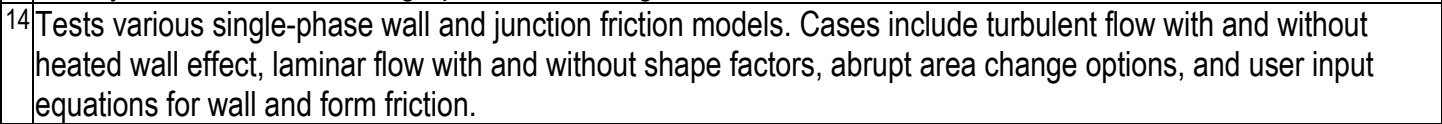 \\
\hline 13.fwhtr & 1 |Represents a tube-in-shell feedwater heater. \\
\hline 14.gota27 & essure steam using radiation enclosure model. \\
\hline
\end{tabular}




\begin{tabular}{|c|c|}
\hline 15.hse & $\begin{array}{l}3 \text { Simulates two-phase flow through a horizontal tee with offtakes coming off the top, bottom, or side face of the } \\
\text { horizontal pipe. }\end{array}$ \\
\hline 16.httable & $\begin{array}{l}3 \text { Simple model of a pipe and heat structure exercising structure BC related to heat flux and heat transfer } \\
\text { coefficient. }\end{array}$ \\
\hline 17.httest & $\begin{array}{l}9 \text { Simple model of a pipe and heat structure that varies IC and BC to achieve various heat transfer regimes for } \\
\text { heat transfer packages } 1,111 \text {, and } 134 \text {. Also tests the non-equilibrium volume option. }\end{array}$ \\
\hline 18.hxco2m & $\begin{array}{l}2 \text { Models a once-through heat exchanger with } \mathrm{PbBi} \text { on the shell side and supercritical carbon dioxide inside the } \\
\text { tubes. Tests the normal and alternate heat structure-fluid coupling models in steady-state. }\end{array}$ \\
\hline 19.jetjun & 2 Simulates insurges and outsurges of liquid into a pressurizer with and without the jet junction model. \\
\hline 20.jetpmp & 1 Tests jet pump performance over a range of suction and driveline flows. \\
\hline 21.131acc & 1 Represents the accumulator response during a slow depressurization during LOFT Experiment L3-1. \\
\hline $\begin{array}{l}\text { 22.12-5-emA } \\
23 .(1)\end{array}$ & $\begin{array}{l}1 \text { Tests Appendix K options during a LOFT Experiment L2-5, which simulates a loss-of-coolant accident initiated } \\
\text { by a large break. }\end{array}$ \\
\hline 24.neptunus & 2 Models pressurizer insurge/outsurge experiment with spray. \\
\hline 25.pack & $\begin{array}{l}4 \text { Vertical fill problem tests water packing model when subcooled liquid is injected into superheated steam from } \\
\text { below. Uses semi- and nearly-implicit timesteps. }\end{array}$ \\
\hline 26.pitch & 1 Tests an inertial check valve with movement. \\
\hline 27.radial & 1|Models pure radial, symmetric flow problem in a 2D hollow cylinder. There is no azim \\
\hline 28.rcpr & 1 |Tests the performance of a recompressing compressor in a supercritical CO2 cycle. \\
\hline 29.refbun & $\begin{array}{l}1 \text { Tests two-phase flow and heat transfer with horizontal and vertical bundles that exercise the Groeneveld and } \\
\text { PG CHF correlations and correlations for narrow, rectangular channels. }\end{array}$ \\
\hline 30.regime & $\begin{array}{l}22 \\
\text { Tests the standard horizontal and vertical flow regimes by adjusting flow boundary conditions through a simple } \\
\text { pipe. Both the pre-CHF and post-CHF regimes are tested for the vertical pipe. }\end{array}$ \\
\hline 31.rigidbody & 1/Models pure azimuthal, symmetric flow problem in a 2D hollow cylinder. There is no radial flow. \\
\hline 32.rtheta & 1 Models flow in a 2D hollow cylinder with symmetric flow in both the radial and azimuthal flow directions. \\
\hline 33.rtsampnm & 1 Based on typpwr, tests radio-nuclide transport model and the axial heat source options using nodal kinetics. \\
\hline 34.rtsamppm & $\begin{array}{l}\text { Based on typpwr with uses point kinetics, tests various axial heat source options, including those from tables, } \\
\text { control variables, and reactor kinetics. Tests the radio-nuclide transport model too }\end{array}$ \\
\hline 35.slab3 & 1 Tests the metal water reaction model for steam flowing past the right surface of a rectangular heat structure. \\
\hline 36.sphere3 & ${ }_{1}^{1}$ Tests the metal water reaction model for steam flowing past the right surface of a spherical heat structure. \\
\hline 37.state & $\begin{array}{l}24 \mid \begin{array}{l}\text { Tests various fluid states, including subcooled liquid, two-phase, superheated vapor, high-pressure liquid, high- } \\
\text { temperature vapor, and supercritical, for h2o, h2on, d2o, and new helium. }\end{array}\end{array}$ \\
\hline 38.todend & 1/Models heat transfer from hot wall with the reflood and two-dimensional heat conduction models. \\
\hline 39.turbine9 & paration. All four types of turbines are tested. \\
\hline 40. typ12002 & 1 |Models small-break LOCA in a typical pressurized water reactor for $1200 \mathrm{~s}$. \\
\hline 41.typ_kindt & 2 TYPPWR input model with nodal kinetics, Krylov solver, and independent kinetics timestep. \\
\hline 42.valve & 5 Models opening and closing of all valves, except relief. \\
\hline 43.varvol2 & 1 Uses the variable volume model and a general table to vary the fluid volume of a single liquid-filled volume. \\
\hline \multicolumn{2}{|r|}{ New Tests Introduced in this project } \\
\hline 44.cpl_det & 1/A simplified version of TYPPWR (test 40) that tests the detector model with pt. kinetics \\
\hline 45.cpl_det_new & 1 Same as cpl_det (test 51) with modified weighting factors and attenuation coefficients. \\
\hline 46.cpl_new_sa & ${ }_{1}^{1}$ A version of TYPPWR (test 40) that tests the detector model with nodal kinetics \\
\hline 47.cpl_pvm_core & $\begin{array}{l}1 \text { Christensen model domain decomposed into two semi-implicitly coupled regions, one with the center of the } \\
\text { pipe representing the core, the other with the upper and lower portions. }\end{array}$ \\
\hline 48.cpl_pvmcs & 1Edward's pipe problem adapted to test control system coupling \\
\hline 49.cpl_pvmeda & 1 Edward's pipe problem split in half to test asynchronous coupling \\
\hline 50.cpl_pvmedca & 1 Edward's pipe problem split in half to test asynchronous explicit conserving coupling \\
\hline 51.cpl_pvmedcs & 1 Edward's pipe problem split in half to test synchronous explicit coupling \\
\hline 52.cpl_pvmnd & 1 A version of TYPPWR (test 40) that tests nodal kinetics coupling \\
\hline 53.cpl_pvmnonc & ${ }_{1}^{1}$ Parallel pipes tests multiple connections to a coupling TDV and multiple noncondensables \\
\hline 54.cpl_pvmpt & ${ }_{1}^{1}$ A version of TYPPWR (test 40) that tests point kinetics coupling \\
\hline 55.det & 1 Tests the detector model. \\
\hline 56.det_new & 1 Tests the detector model. \\
\hline 57.do_nothing & 1 Tests if zero flow and zero heat transfer are maintained in a rectangular solid of $3 \times 5$ vols. constructed of 5 \\
\hline
\end{tabular}




\begin{tabular}{|l|l|l|}
\hline & volume pipes connected by multiple junctions. \\
\hline 58.ht_expl_fluid & 1 & Tests explicit fluid-to-heat structure coupling \\
\hline 59.ht_imp_fluid & 1 & Tests implicit fluid-to-heat structure coupling \\
\hline 60.nothing_trans & 1 & $\begin{array}{l}\text { Tests moving problems translational acceleration specified by both periodic and table input in a 3×3×5 } \\
\text { rectangular solid built of } 5 \text { volume pipes connected by multiple junctions. }\end{array}$ \\
\hline 61.pvmcore & 1 & Tests ability of RELAP5-3D to run the vessel interior of a modified Christensen model[8, 9]. \\
\hline 62.pvmcs & 1 Edward's pipe problem adapted to test control system \\
\hline 63.pvmnonc & 1 & Parallel pipes tests multiple connections to TDV and multiple noncondensables \\
\hline 64.pvmpt & 1 A version of TYPPWR (test 40) that tests point kinetics \\
\hline 65.tdvtdj & 1 & Tests multiple connections to a TDV. \\
\hline
\end{tabular}




\subsection{Features and Cases Matrix}

A review of the code's capabilities and features that are commonly used in performing reactor and associated system simulations was performed. The important categories of code features and models included hydrodynamic components, volume and junction options, heat structure types, correlations, boundary conditions, trips, tables, control variables, reactor kinetics, Appendix K, and user choices that affect the way the code operates. Among user choices are time advancement scheme, solver, card 1 options and many others.

Features identified in the initial report are the same ones used for this report with a few extras.

Input cases include those from the original report and a number of new cases of interest. Because of the additional cases, Features-Cases Matrix is too long and wide to represent legibly across a page. To accommodate the information, the features are broken into 6 sub-tables. The cases are broken in half with the old cases presented in part "a" of each sub-table followed on the next page by the new cases reported in sub-table "b." For example, Table 3.2.1a holds the components for the original cases and Table 3.2.1b has the 22 new cases. Since the automated system does not detect everything, there are many blank rows.

Both Fortran and Linux script coding was improved to find more of the tested features and place them in the CSV version of the Features-Cases Matrix. Still, not all features are detected automatically. For those that are, an ' $\mathrm{M}$ ' for Machine-identified is placed beneath the case name in the row of the feature detected. As always, an " $\mathrm{X}$ " in Column two indicates the feature is tested by at least one member of the suite of cases and an " $X$ " in Column three indicates feature is restarted. These marks are "carried over" from the rest of the matrix, and indicate testing among all 65 cases, not just the new cases. Items marked in purple are not tested and, though of some value in modeling some nuclear power plants, are of lesser importance, have very few applications, or can be modeled through other means with RELAP5-3D. 
Table 3.2.1a. Features-Cases Matrix - Hydrodynamic Components

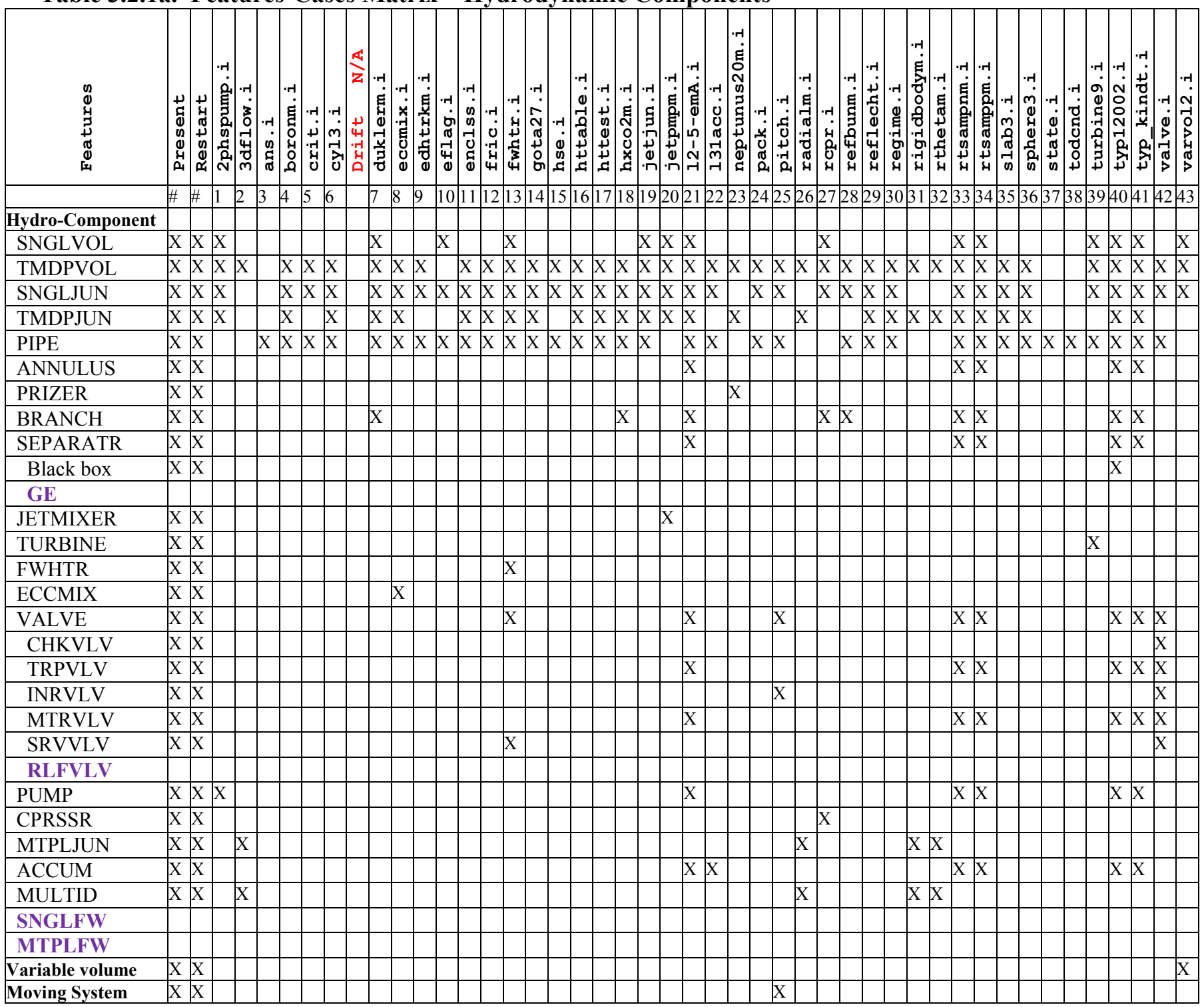


Table 3.2.1b. Features-Cases Matrix - Hydrodynamic Components

\begin{tabular}{|c|c|c|c|c|c|c|c|c|c|c|c|c|c|c|c|c|c|c|c|c|}
\hline 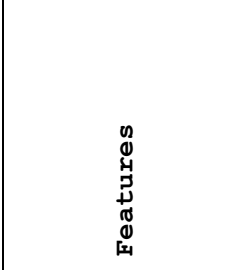 & 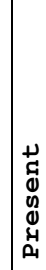 & 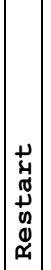 & 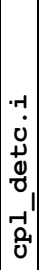 & 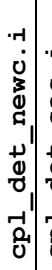 & 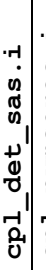 & 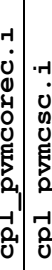 & 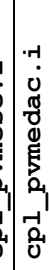 & 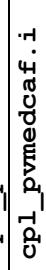 & 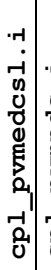 & 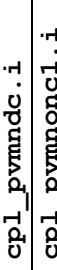 & 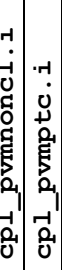 & 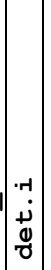 & 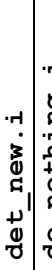 & 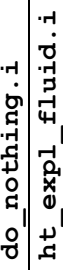 & 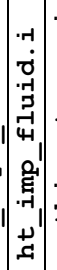 & 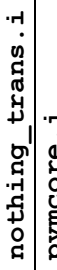 & 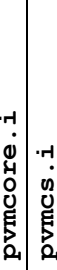 & 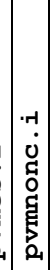 & 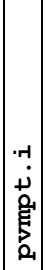 & 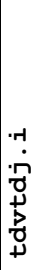 \\
\hline & \# & $\#$ & 44 & 454 & 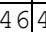 & 4748 & $8 \longdiv { 4 9 }$ & 950 & 515 & \begin{tabular}{l|l}
52 & 5
\end{tabular} & \begin{tabular}{|l|l|}
5354 \\
\end{tabular} & 55 & $\begin{array}{l}56 / 5 \\
-19\end{array}$ & $\begin{array}{ll}5758 \\
\end{array}$ & 3596 & \begin{tabular}{l|l}
60 & 6
\end{tabular} & 6162 & \begin{tabular}{|l|}
263 \\
63
\end{tabular} & 64 & 65 \\
\hline Hydro-Component & & & & & & & & & & & & & & & & & & & & \\
\hline SNGLVOL & $\mathrm{X}$ & $\mathrm{X}$ & $\mathrm{M}$ & $\mathrm{M}$ & $\mathrm{M}$ & $\mathrm{M}$ & & & & $\mathrm{M}$ & $\mathrm{M}$ & $\mathrm{M}$ & $\mathrm{M}$ & & & & $\mathrm{M}$ & & $\mathrm{M}$ & \\
\hline TMDPVOL & $\mathrm{X}$ & $\mathrm{X}$ & & & $\mathrm{M}$ & $\mathrm{N}$ & M $\mathrm{M}$ & $1 \mathrm{M}$ & $\mathrm{M}$ & & \begin{tabular}{l|l}
$\mathrm{M}$ \\
\end{tabular} & $\mathrm{M}$ & $\mathrm{M}$ & $\mathrm{M}$ & $\mathrm{M}$ & & \begin{tabular}{l|l}
$\mathrm{M}$ & $\mathrm{M}$ \\
\end{tabular} & & $\mathrm{M}$ & $\mathrm{M}$ \\
\hline SNGLJUN & $\mathrm{X}$ & $\mathrm{X}$ & $\mathrm{M}$ & $\mathrm{M}$ & $\mathrm{M}$ & $\mathrm{M}$ & & & $\mathrm{M}$ & \begin{tabular}{l|l}
$\mathrm{M}$ & $\mathrm{I}$ \\
\end{tabular} & \begin{tabular}{|l|l|}
$M$ & $M$ \\
\end{tabular} & $\mathrm{M}$ & $\mathrm{M}$ & $\mathrm{M}$ & $\mathrm{M}$ & & \begin{tabular}{l|l}
$\mathrm{M}$ & $\mathrm{M}$ \\
\end{tabular} & & $\mathrm{M}$ & M \\
\hline TMDPJUN & $\mathrm{X}$ & $\mathrm{X}$ & & & $\mathrm{M}$ & $\mathrm{N}$ & $\begin{array}{l}\mathrm{M} \\
\mathrm{M}\end{array}$ & $1 \mathrm{M}$ & & & & $\mathrm{M}$ & $\mathrm{M}$ & $\mathrm{M}$ & $\mathrm{M}$ & & & & $\mathrm{M}$ & $\mathrm{M}$ \\
\hline PIPE & $\mathrm{X}$ & $\mathrm{X}$ & $\mathrm{M}$ & $\mathrm{M}$ & $\mathrm{M}$ & \begin{tabular}{l|l}
$\mathrm{M}$ & $\mathrm{N}$ \\
\end{tabular} & $\begin{array}{ll}\mathrm{M} & \mathrm{M} \\
\end{array}$ & 1) & $\mathrm{M}$ & $\mathrm{M} \mid \mathrm{I}$ & $\begin{array}{ll}\mathrm{M} & \mathrm{M} \\
\end{array}$ & $\mathrm{M}$ & $\mathrm{M}$ & \begin{tabular}{l|l}
$M$ & $M$ \\
\end{tabular} & $\mathrm{M}$ & \begin{tabular}{l|l}
$\mathrm{M}$ & $\mathrm{I}$ \\
\end{tabular} & $\mathrm{M}$ & a $\mathrm{M}$ & $\mathrm{M}$ & $\mathrm{M}$ \\
\hline ANNULUS & $\mathrm{X}$ & $\mathrm{X}$ & & & $\mathrm{M}$ & & & & & & & $\mathrm{M}$ & $\mathrm{M}$ & & & & & & $\mathrm{M}$ & \\
\hline PRIZER & $\mathrm{X}$ & $\mathrm{X}$ & & & & & & & & & & & & & & & & & & \\
\hline BRANCH & $\mathrm{X}$ & $\mathrm{X}$ & & & $\mathrm{M}$ & & & & & & & $\mathrm{M}$ & $\mathrm{M}$ & & & & & & $\mathrm{M}$ & \\
\hline SEPARATR & $\mathrm{X}$ & $\mathrm{X}$ & & & $\mathrm{M}$ & & & & & & & $\mathrm{M}$ & $\mathrm{M}$ & & & & & & $\mathrm{M}$ & \\
\hline Black box & $\mathrm{X}$ & $\mathrm{X}$ & & & & & & & & & & & & & & & & & & \\
\hline GE & & & & & & & & & & & & & & & & & & & & \\
\hline JETMIXER & $\mathrm{X}$ & $\mathrm{X}$ & & & & & & & & & & & & & & & & & & \\
\hline TURBINE & $\mathrm{X}$ & $\mathrm{X}$ & & & & & & & & & & & & & & & & & & \\
\hline FWHTR & $\mathrm{X}$ & $\mathrm{X}$ & & & & & & & & & & & & & & & & & & \\
\hline ECCMIX & $\mathrm{X}$ & $\mathrm{X}$ & & & & & & & & & & & & & & & & & & \\
\hline VALVE & $\mathrm{X}$ & $\mathrm{X}$ & & & $\mathrm{M}$ & & & & & & & $\mathrm{M}$ & $\mathrm{M}$ & & & & & & $\mathrm{M}$ & \\
\hline CHKVLV & $\mathrm{X}$ & $\mathrm{X}$ & & & & & & & & & & & & & & & & & & \\
\hline TRPVLV & $\mathrm{X}$ & $\mathrm{X}$ & & & $\mathrm{M}$ & & & & & & & $\mathrm{M}$ & $\mathrm{M}$ & & & & & & $\mathrm{M}$ & \\
\hline INRVLV & $\mathrm{X}$ & $\mathrm{X}$ & & & & & & & & & & & & & & & & & & \\
\hline MTRVLV & $\mathrm{X}$ & $\mathrm{X}$ & & & $\mathrm{M}$ & & & & & & & $\mathrm{M}$ & $\mathrm{M}$ & & & & & & $\mathrm{M}$ & \\
\hline SRVVLV & $\mathrm{X}$ & $\mathrm{X}$ & & & & & & & & & & & & & & & & & & \\
\hline RLFVLV & & & & & & & & & & & & & & & & & & & & \\
\hline PUMP & $\mathrm{X}$ & $\mathrm{X}$ & & & $\mathrm{M}$ & & & & & & $\mathrm{M}$ & $\mathrm{M}$ & $\mathrm{M}$ & & & & & $\mathrm{M}$ & $\mathrm{M}$ & \\
\hline CPRSSR & $\mathrm{X}$ & $\mathrm{X}$ & & & & & & & & & & & & & & & & & & \\
\hline MTPLJUN & $\mathrm{X}$ & $\mathrm{X}$ & & & & & & & & & & & & $\mathrm{M}$ & & $\mathrm{M}$ & & & & \\
\hline ACCUM & $\mathrm{X}$ & $\mathrm{X}$ & & & $\mathrm{M}$ & & & & & & & $\mathrm{M}$ & $\mathrm{M}$ & & & & & & $\mathrm{M}$ & \\
\hline MULTID & $\mathrm{X}$ & $\mathrm{X}$ & & & & & & & & & & & & & & & & & & \\
\hline SNGLFW & & & & & & & & & & & & & & & & & & & & \\
\hline MTPLFW & & & & & & & & & & & & & & & & & & & & \\
\hline Variable volume & $\mathrm{X}$ & $\mathrm{X}$ & & & & & & & & & & & & & & & & & & $x$ \\
\hline Moving System & $\mathrm{X}$ & $\mathrm{X}$ & & & & & & & & & & & & & & $\mathrm{M}$ & & & & \\
\hline
\end{tabular}


Table 3.2.2a. Features-Cases Matrix - Component Control \& Specification

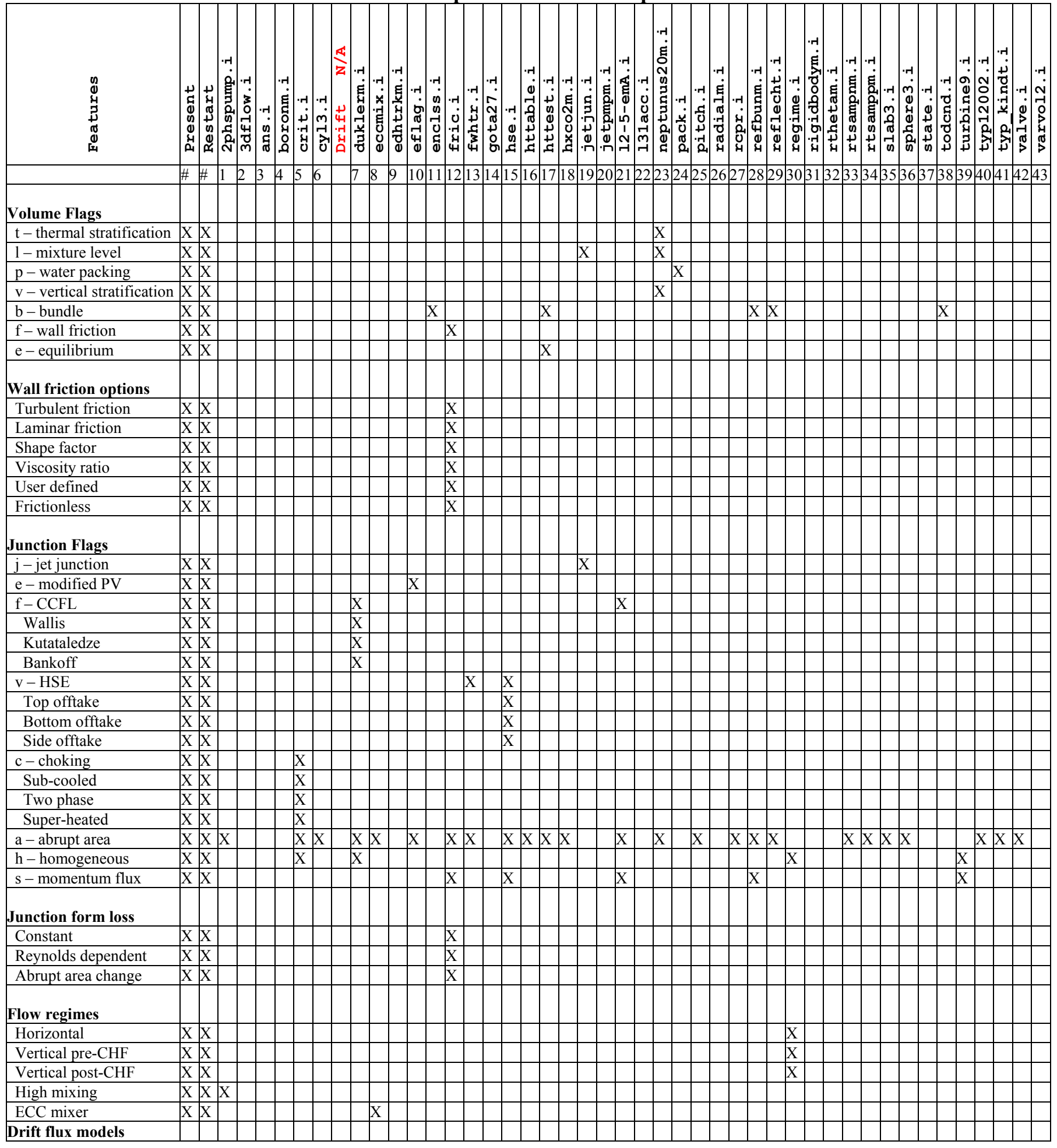


Table 3.2.2b. Features-Cases Matrix - Component Control \& Specification

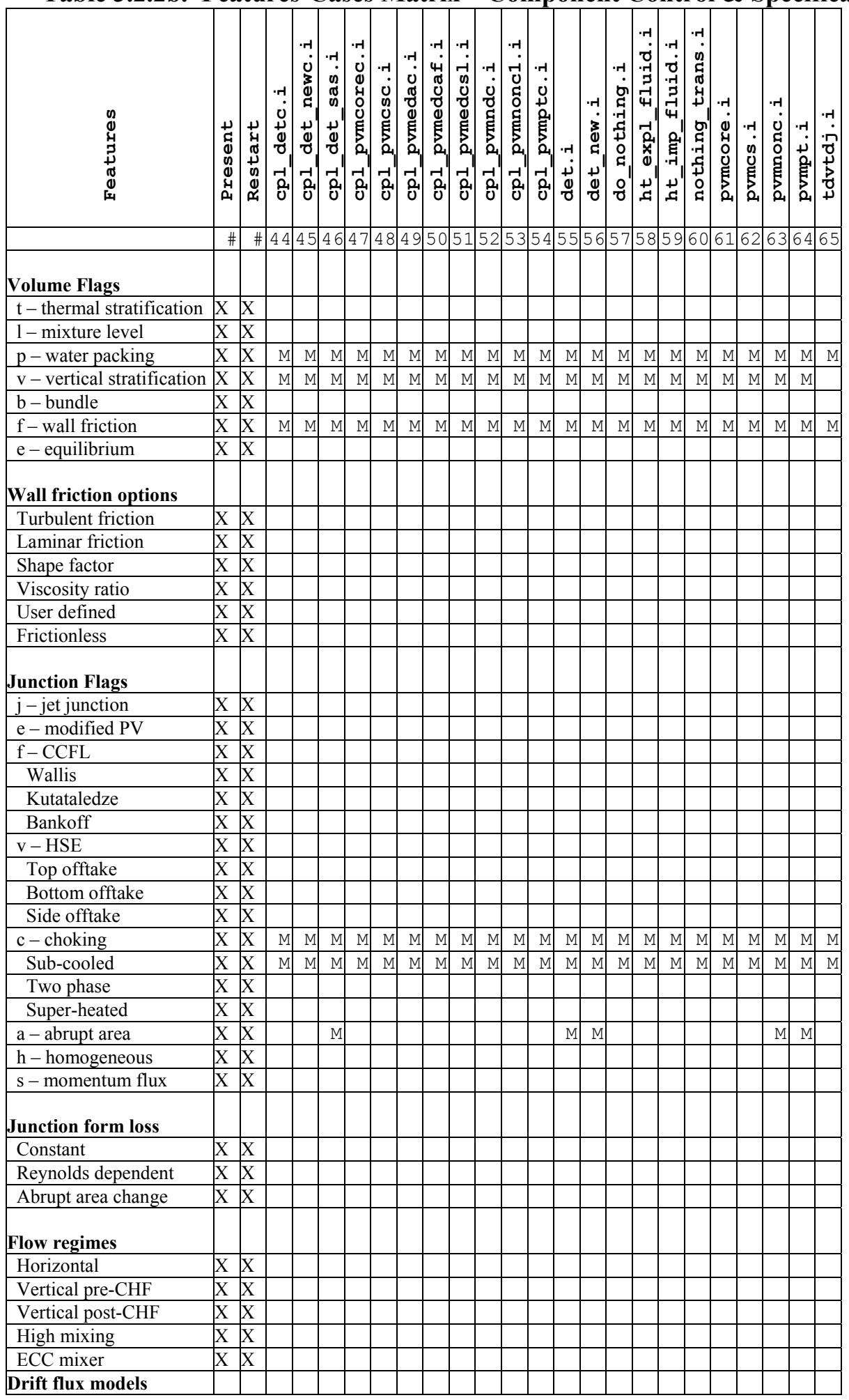


Table 3.2.3a. Features-Cases Matrix - Heat Transfer Specification

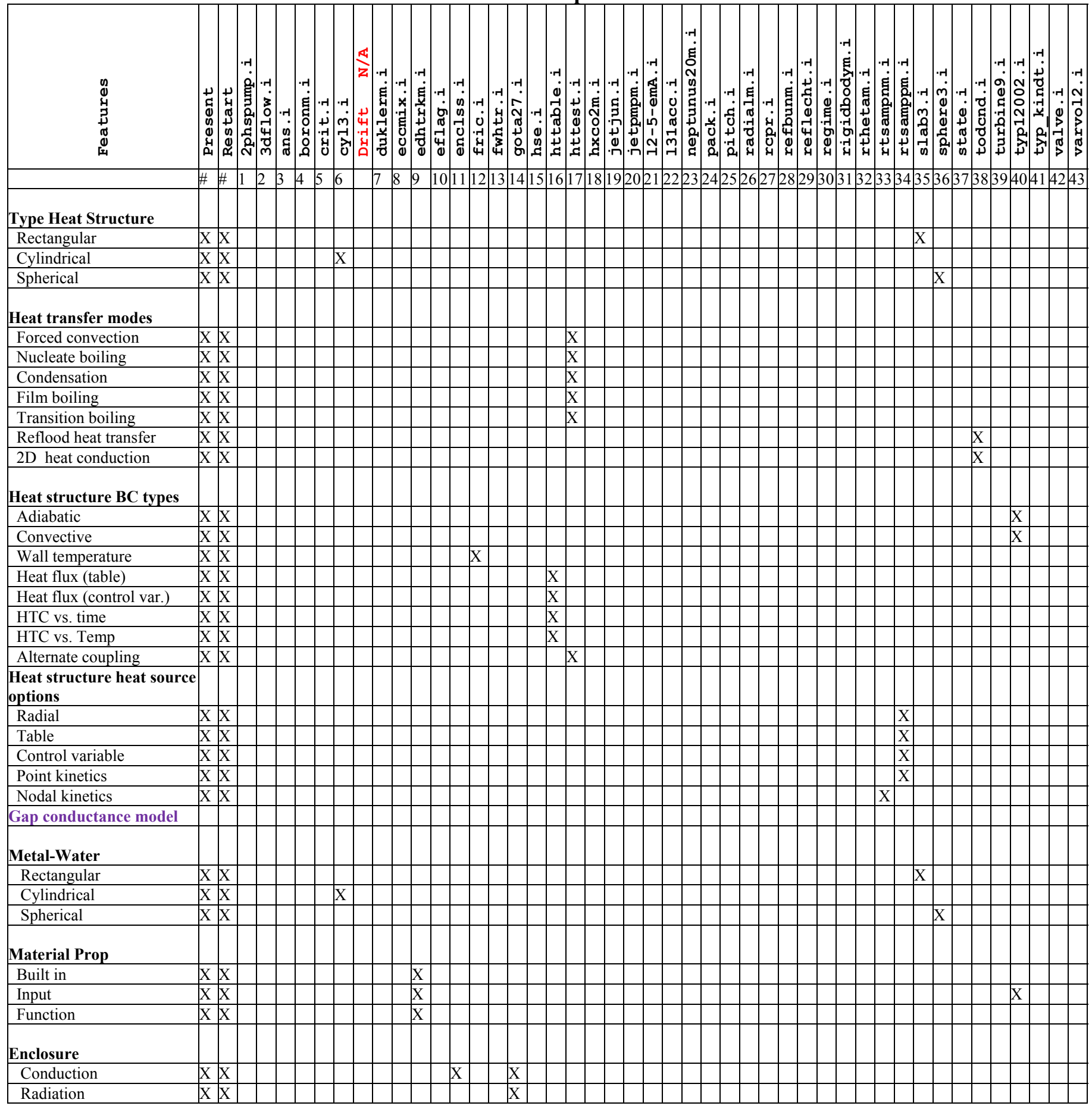


Table 3.2.3b. Features-Cases Matrix - Heat Transfer Specification

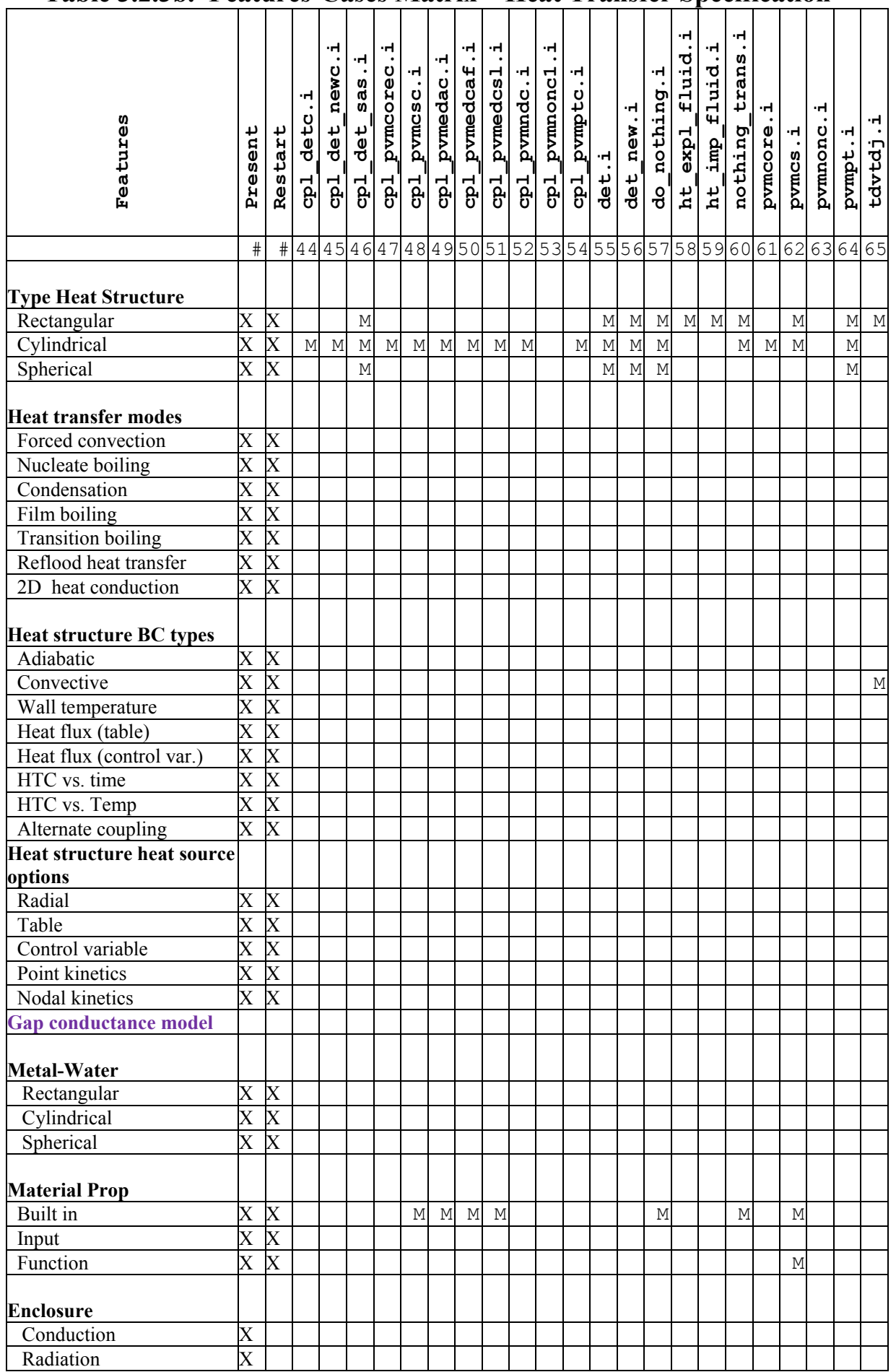


Table 3.2.4a. Features-Cases Matrix - Tables and Kinetics

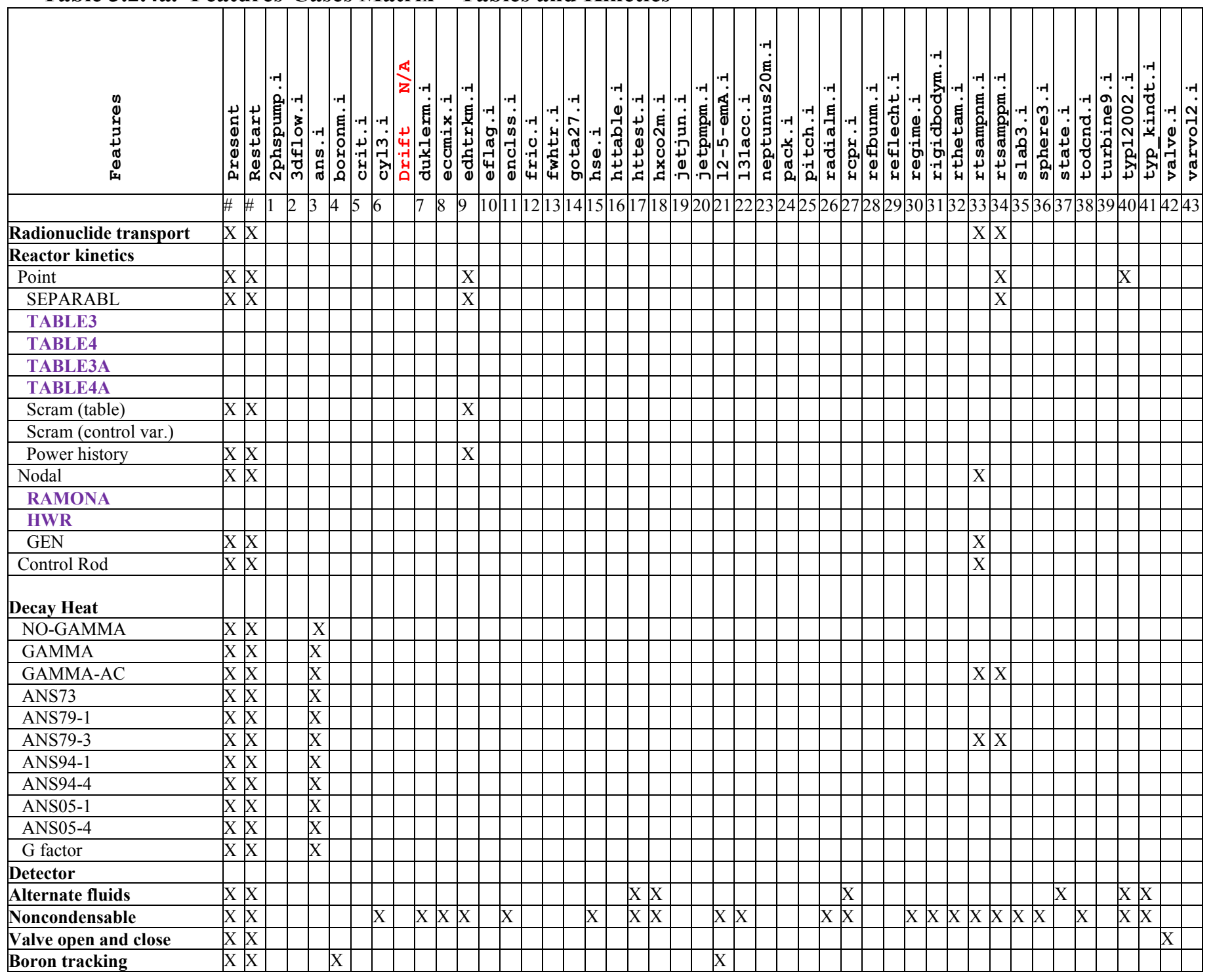


Table 3.2.4b. Features-Cases Matrix - Tables and Kinetics

\begin{tabular}{|c|c|c|c|c|c|c|c|c|c|c|c|c|c|c|c|c|c|c|c|c|}
\hline 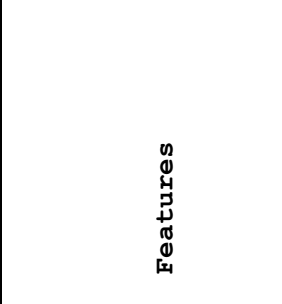 & 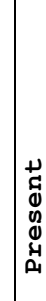 & $\begin{array}{l}+ \\
4 \\
\pi \\
4 \\
0 \\
ه \\
\sim\end{array}$ & 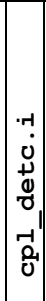 & 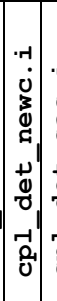 & 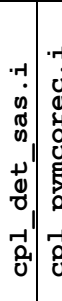 & 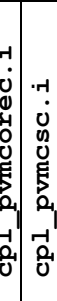 & $\begin{array}{c}-4 \\
0 \\
0 \\
0 \\
0 \\
0 \\
5 \\
0.2 \\
-1 \\
0 \\
0\end{array}$ & 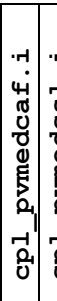 & 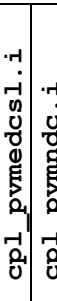 & 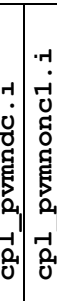 & 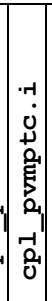 & 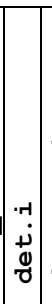 & | & 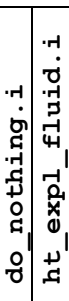 & 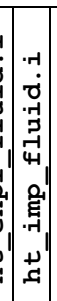 & 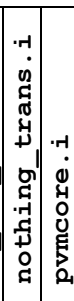 & 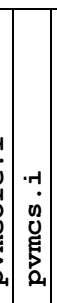 & 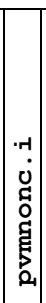 & 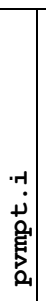 & r. \\
\hline & \# & $\#$ & 44 & 454 & $\begin{array}{lll}464 \\
\end{array}$ & 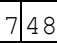 & 49 & 505 & \begin{tabular}{l|l}
51 & 52
\end{tabular} & 5253 & 54 & 55 & 565 & \begin{tabular}{l|l}
57 & 58
\end{tabular} & 859 & 6061 & 162 & 63 & 64 & 65 \\
\hline Radionuclide transport & $\mathrm{X}$ & $\mathrm{X}$ & & & & & & & & & & & & & & & & & & \\
\hline Reactor kinetics & & & & & & & & & & & & & & & & & & & & \\
\hline \begin{tabular}{|l|} 
Point \\
\end{tabular} & $\mathrm{X}$ & $\mathrm{X}$ & & & & & & & & & & & & & & & $\mathrm{M}$ & & $\mathrm{M}$ & \\
\hline SEPARABL & $\mathrm{X}$ & $\mathrm{X}$ & & & & & & & & & & & & & & & $\mathrm{M}$ & & $\mathrm{M}$ & \\
\hline TABLE3 & & & & & & & & & & & & & & & & & & & & \\
\hline TABLE4 & & & & & & & & & & & & & & & & & & & & \\
\hline TABLE3A & & & & & & & & & & & & & & & & & & & & \\
\hline TABLE4A & & & & & & & & & & & & & & & & & & & & \\
\hline Scram (table) & $\mathrm{X}$ & $\mathrm{X}$ & & & & & & & & & & & & & & & & & & \\
\hline Scram (control var.) & & & & & & & & & & & & & & & & & & & & \\
\hline Power history & $\mathrm{X}$ & $\mathrm{X}$ & & & & & & & & & & & & & & & & & & \\
\hline Nodal & $\mathrm{X}$ & $\mathrm{X}$ & & & $\mathrm{M}$ & & & & & & & $\mathrm{M}$ & $\mathrm{M}$ & & & & & & & \\
\hline RAMONA & & & & & & & & & & & & & & & & & & & & \\
\hline HWR & & & & & & & & & & & & & & & & & & & & \\
\hline GEN & $\mathrm{X}$ & $\mathrm{X}$ & & & $\mathrm{M}$ & & & & & & & $\mathrm{M}$ & $\mathrm{M}$ & & & & & & & \\
\hline Control Rod & $\mathrm{X}$ & $\mathrm{X}$ & & & & & & & & & & & & & & & & & & \\
\hline Decay Heat & & & & & & & & & & & & & & & & & & & & \\
\hline NO-GAMMA & $\mathrm{X}$ & $\mathrm{X}$ & & & & & & & & & & & & & & & & & & \\
\hline GAMMA & $\mathrm{X}$ & $\mathrm{X}$ & & & $\mathrm{M}$ & & & & & & & $\mathrm{M}$ & $\mathrm{M}$ & & & & $\mathrm{M}$ & & $\mathrm{M}$ & \\
\hline GAMMA-AC & $\mathrm{X}$ & $\mathrm{X}$ & & & $\mathrm{M}$ & & & & & & & $\mathrm{M}$ & $\mathrm{M}$ & & & & $\mathrm{M}$ & & $\mathrm{M}$ & \\
\hline ANS73 & $\mathrm{X}$ & $\mathrm{X}$ & & & & & & & & & & & & & & & & & & \\
\hline ANS79-1 & $\mathrm{X}$ & $\mathrm{X}$ & & & $\mathrm{M}$ & & & & & & & $\mathrm{M}$ & $\mathrm{M}$ & & & & & & $\mathrm{M}$ & \\
\hline ANS79-3 & $\mathrm{X}$ & $\mathrm{X}$ & & & & & & & & & & & & & & & & & & \\
\hline ANS94-1 & $\mathrm{X}$ & $\mathrm{X}$ & & & & & & & & & & & & & & & & & & \\
\hline ANS94-4 & $\mathrm{X}$ & $\mathrm{X}$ & & & & & & & & & & & & & & & & & & \\
\hline ANS05-1 & $\mathrm{X}$ & $\mathrm{X}$ & & & & & & & & & & & & & & & & & & \\
\hline ANS05-4 & $\mathrm{X}$ & $\mathrm{X}$ & & & & & & & & & & & & & & & & & & \\
\hline $\mathrm{G}$ factor & $\mathrm{X}$ & $\mathrm{X}$ & & & & & & & & & & & & & & & & & & \\
\hline Detector & & $\mathrm{X}$ & & & & & & & & & & $\mathrm{x}$ & $\mathrm{x}$ & & & & & & & \\
\hline \begin{tabular}{|l} 
Alternate fluids \\
\end{tabular} & $\mathrm{X}$ & $\mathrm{X}$ & & & & & & & & & & & & & & & & & & \\
\hline Noncondensable & $\mathrm{X}$ & $\mathrm{X}$ & & & & & & & & & & & & & & & & & & \\
\hline Valve open and close & $\mathrm{X}$ & $\mathrm{X}$ & & & & & & & & & & & & & & & & & & \\
\hline Boron tracking & $\mathrm{X}$ & $\mathrm{X}$ & & & & & & & & & & & & & & & & & & \\
\hline
\end{tabular}


Table 3.2.5a. Features-Cases Matrix - Trips and Controls

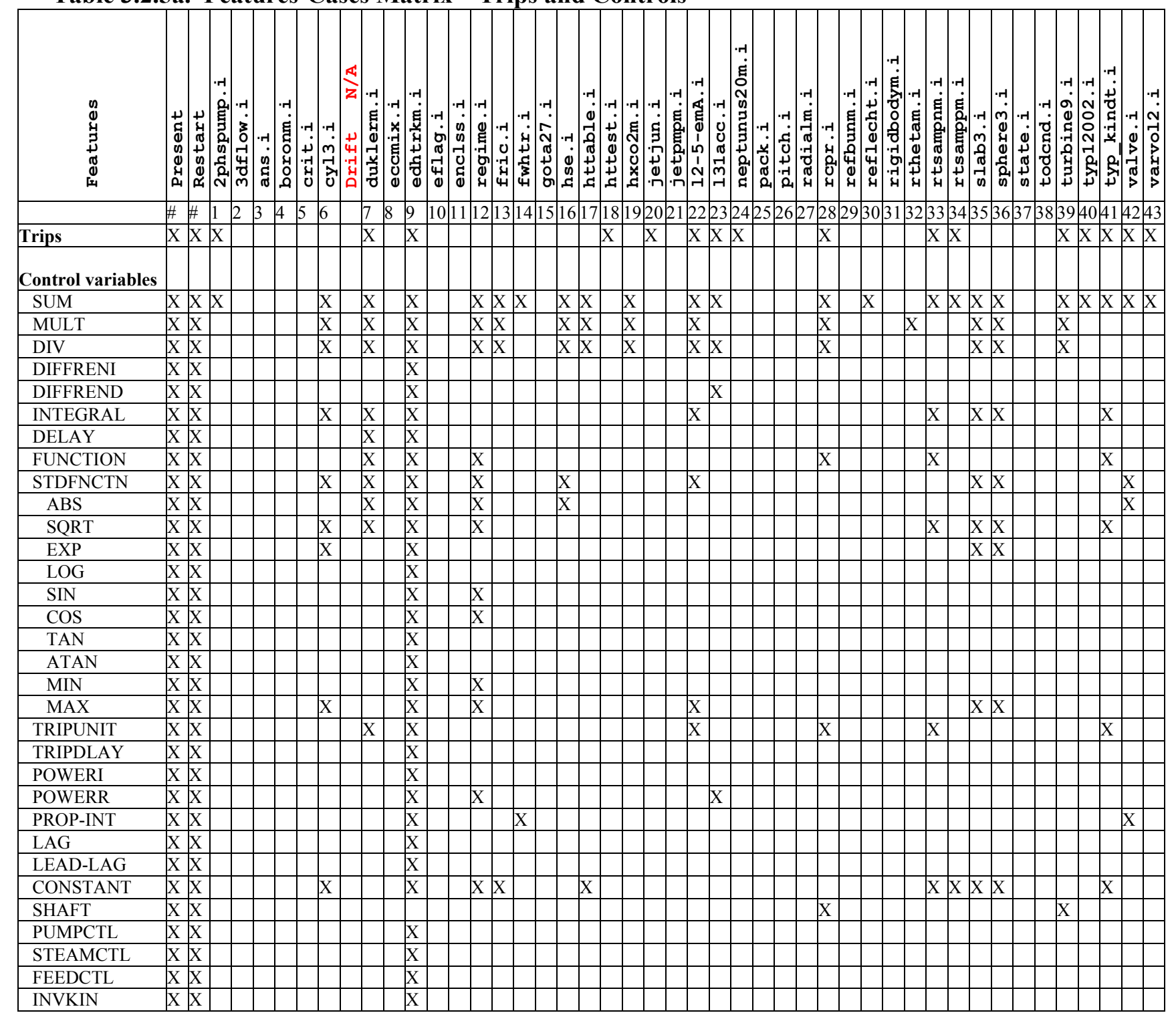


Table 3.2.5b. Features-Cases Matrix - Trips and Controls

\begin{tabular}{|c|c|c|c|c|c|c|c|c|c|c|c|c|c|c|c|c|c|c|c|c|}
\hline & & & & & & & & & & & & & & & & & & & & \\
\hline 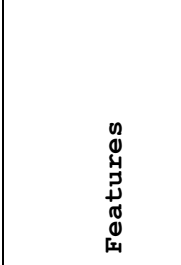 & 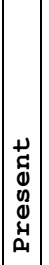 & 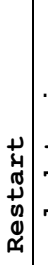 & 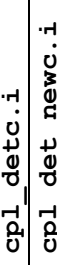 & 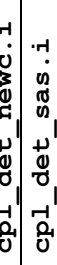 & 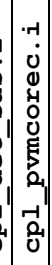 & 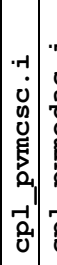 & 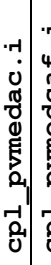 & 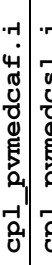 & & 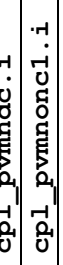 & 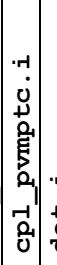 & 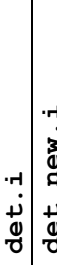 & 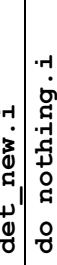 & 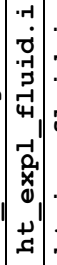 & 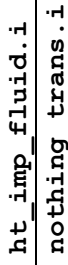 & & 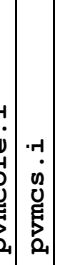 & 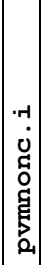 & 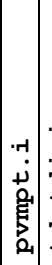 & 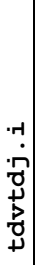 \\
\hline & \# & $\# 4$ & 4445 & 546 & 647 & 484 & 495 & 505 & 5152 & 253 & 545 & $55 \sqrt{5}$ & 5657 & 585 & 5960 & 5061 & \begin{tabular}{l|l|}
1 & 62 \\
\end{tabular} & 63 & 646 & 65 \\
\hline Trips & $\mathrm{X} 2$ & \begin{tabular}{|l|l} 
\\
\end{tabular} & & $\begin{array}{ll} \\
\end{array}$ & $\mathrm{M}$ & $\mathrm{M}$ & $\mathrm{M}$ & $\mathrm{M}$ & $\mathrm{M}$ & $\mathrm{M}$ & & $\mathrm{M} / \mathrm{I}$ & \begin{tabular}{l|l}
$\mathrm{M}$ \\
\end{tabular} & & & & $\mathrm{M}$ & $\mathrm{M}$ & $\mathrm{M}$ & \\
\hline Control variab & & & & & & & & & & & & & & & & & & & & \\
\hline SUM & $\mathrm{X} \mid \mathrm{z}-2$ & $\mathrm{X}$ & \begin{tabular}{l|l}
$M$ & $\mathrm{~N}$ \\
\end{tabular} & \begin{tabular}{l|l}
$\mathrm{M}$ & $\mathrm{M}$ \\
\end{tabular} & $\mathrm{M}$ & $\mathrm{M}$ & $\mathrm{M} \mid$ & $\mathrm{M} / \mathrm{I}$ & $\mathrm{M}$ & & $\mathrm{M}$ & $\mathrm{M}$ & $\mathrm{M}$ & & & & $\mathrm{M}$ & & $\mathrm{M}$ & $\mathrm{M}$ \\
\hline MULT & 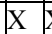 & $\mathrm{X}$ & & & & & $\mathrm{M}$ & $\begin{array}{lll}\mathrm{M} & \mathrm{I} \\
\end{array}$ & $\mathrm{M}$ & & & & & & & & $\mathrm{M}$ & & & \\
\hline DIV & 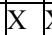 & $\bar{X}$ & & & & 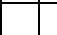 & & & & & & & & & & & $\mathrm{M}$ & & & \\
\hline DIFFRENI & $x+2$ & $\bar{X}$ & & & & & & & & & & & & & & & & & & \\
\hline DIFFREND & $x \mid z$ & $\mathrm{X}$ & & & & & & & & & & & & & & & & & & \\
\hline INTEGRAL & $\begin{array}{ll}X \\
X\end{array}$ & $\bar{X}$ & & $\mathrm{M}$ & $\mathrm{M}$ & $\mathrm{M}$ & & & & & & $\mathrm{M} \mid \mathrm{N}$ & $\mathrm{M}$ & & & & $\mathrm{M}$ & & & \\
\hline DELAY & 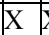 & $\bar{X}$ & & & & $\mathrm{M}$ & & & & & & . & . & & & & $\mathrm{M}$ & & & \\
\hline FUNCTION & $\mathrm{X} \mid \mathrm{z}$ & $\mathrm{X}$ & & $\mathrm{M}$ & $\mathrm{M}$ & $\mathrm{M}$ & & & & & & \begin{tabular}{l|l}
$\mathrm{M}$ & $\mathrm{I}$ \\
\end{tabular} & $\mathrm{M}$ & & & & $\mathrm{M}$ & & & \\
\hline STDFNCTN & $\begin{array}{ll}X \\
X\end{array}$ & $\bar{X}$ & & & & $\mathrm{M}$ & & & & & & & & & & & $\mathrm{M}$ & & & \\
\hline ABS & 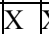 & $\mathrm{X}$ & & & & & & & & & & & & & & & & & & \\
\hline SQRT & $x \mid z$ & $\mathrm{X}$ & & & & & & & & & & & & & & & & & & \\
\hline EXP & 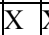 & $\mathrm{X}$ & & & & & & & & & & & & & & & & & & \\
\hline$\overline{L O G}$ & $x+2$ & $\mathrm{X}$ & & & & & & & & & & & & & & & & & & \\
\hline SIN & $x \mid z$ & $\mathrm{X}$ & & & & $\mathrm{M}$ & & & & & & & & & & & $\mathrm{M}$ & & & \\
\hline COS & $\mathrm{X} \mid \mathrm{z}$ & $\mathrm{X}$ & & & & & & & & & & & & & & & & & & \\
\hline TAN & 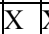 & $\mathrm{X}$ & & & & & & & & & & & & & & & & & & \\
\hline ATAN & $x \mid z$ & $\mathrm{X}$ & & & & & & & & & & & & & & & & & & \\
\hline MIN & $\mathrm{X} \mid \mathrm{z}$ & $\mathrm{X}$ & & & & & & & & & & & & & & & & & & \\
\hline MAX & 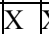 & $\mathrm{X}$ & & & & & & & & & & & & & & & & & & \\
\hline TRIPUNIT & $\mathrm{X} \mid \mathrm{z}$ & $\mathrm{X}$ & & $\mathrm{M}$ & $\mathrm{M}$ & $\mathrm{M}$ & $\mathrm{M}$ & $\begin{array}{lll}\mathrm{M} & \mathrm{I} \\
\end{array}$ & $\mathrm{M}$ & & & \begin{tabular}{l|l}
$\mathrm{N}$ & $\mathrm{I}$
\end{tabular} & $\mathrm{M}$ & & & & $\mathrm{M}$ & & & \\
\hline TRIPDLAY & $\mathrm{X} \mid \mathrm{z}$ & $\mathrm{X}$ & & & & $\mathrm{M}$ & & & & & & & & & & & $\mathrm{M}$ & & & \\
\hline POWERI & 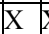 & $\mathrm{X}$ & & & & $\mathrm{M}$ & & & & & & & & & & & $\mathrm{M}$ & & & \\
\hline POWERR & $x \mid 2$ & $\mathrm{X}$ & & & & $\mathrm{M}$ & & & & & & & & & & & $\mathrm{M}$ & & & \\
\hline PROP-INT & $x \mid z$ & $\mathrm{X}$ & & & & $\mathrm{M}$ & & & & & & & & & & & $\mathrm{M}$ & & & \\
\hline LAG & 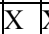 & $\mathrm{X}$ & & & & $\mathrm{M}$ & & & & & & & & & & & $\mathrm{M}$ & & & \\
\hline LEAD-LAG & $\mathrm{X} \mid \mathrm{z}$ & & & & & $\mathrm{M}$ & & & & & & & & & & & $\mathrm{M}$ & & & \\
\hline CONSTANT & $x \mid z$ & $\mathrm{X}$ & & $\mathrm{M}$ & $\mathrm{M}$ & $\mathrm{M}$ & & & & & & \begin{tabular}{l|l}
$\mathrm{M}$ & $\mathrm{I}$ \\
\end{tabular} & $\mathrm{M}$ & & & & $\mathrm{M}$ & & & \\
\hline SHAFT & $\mathrm{X} \mid 2$ & & & & & & & & & & & & & & & & & & & \\
\hline PUMPCTL & $\mathrm{X} \mid \mathrm{z}$ & & & & & $\mathrm{M}$ & & & & & & & & & & & $\mathrm{M}$ & & & \\
\hline STEAMCTL & $x \mid z$ & & & & & $\mathrm{M}$ & & & & & & & & & & & $\mathrm{M}$ & & & \\
\hline $\begin{array}{l}\text { FEEDCTL } \\
\end{array}$ & 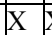 & & & & & $\mathrm{M}$ & & & & & & & & & & & $\mathrm{M}$ & & & \\
\hline INVKIN & 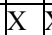 & & & & & & & & & & & & & & & & & & & \\
\hline
\end{tabular}


Table 3.2.6a. Features-Cases Matrix - Code Operation Control \& Misc.

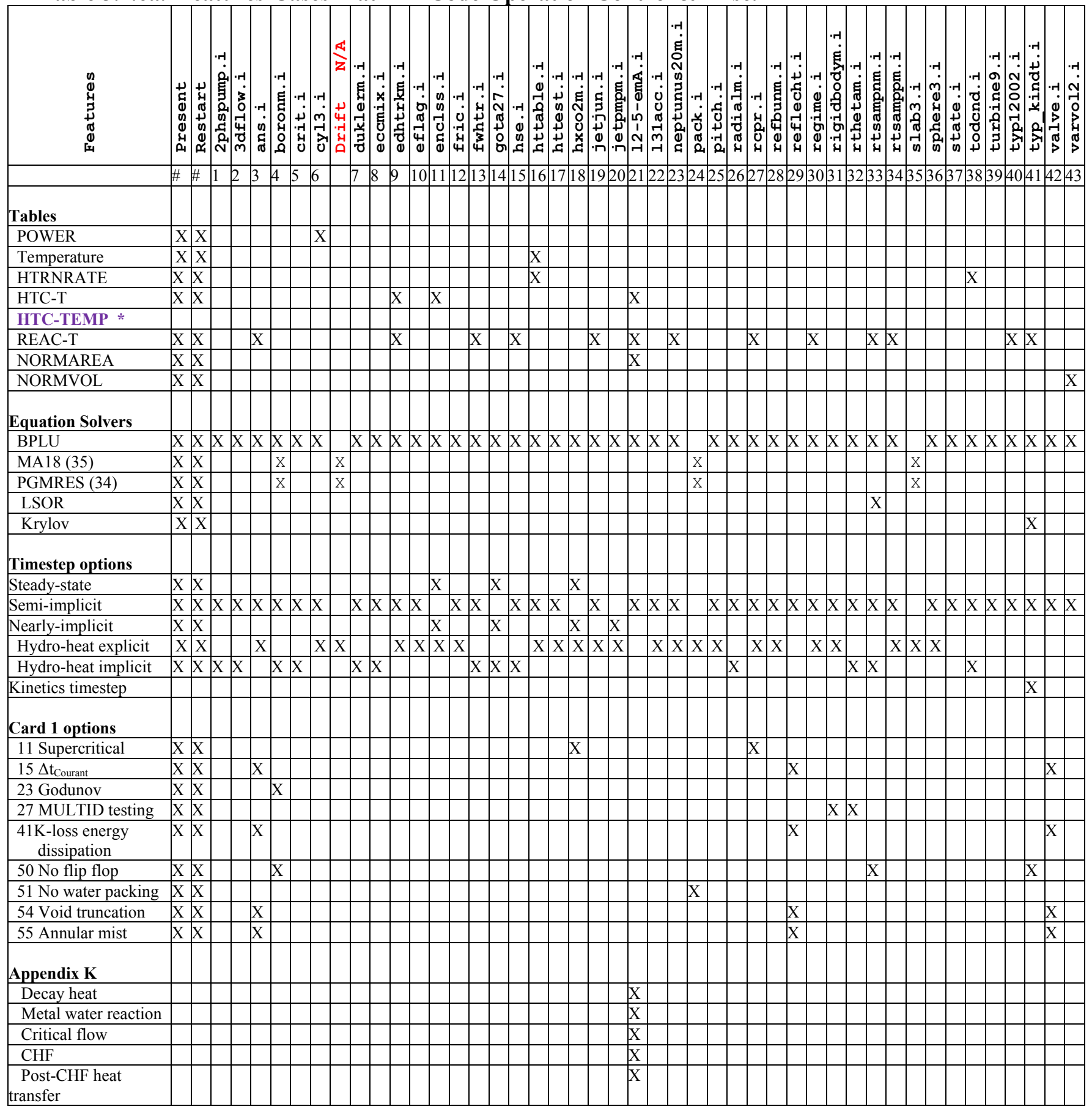


Table 3.2.6b. Features-Cases Matrix - Code Operation Control \& Misc.

\begin{tabular}{|c|c|c|c|c|c|c|c|c|c|c|c|c|c|c|c|c|c|c|c|}
\hline & & & & & & & & & & & & & & & & & & & \\
\hline 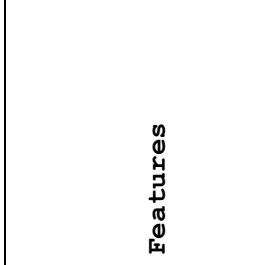 & $\begin{array}{l}4 \\
0 \\
0 \\
0 \\
0 \\
0 \\
0\end{array}$ & 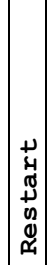 & 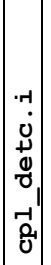 & 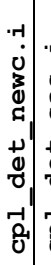 & 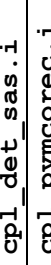 & 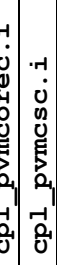 & 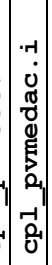 & 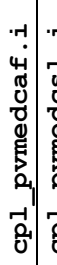 & 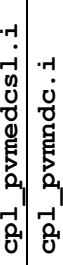 & 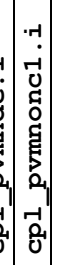 & 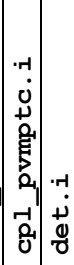 & 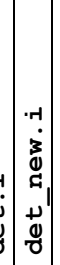 & 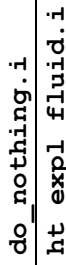 & 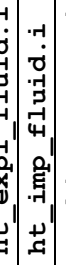 & 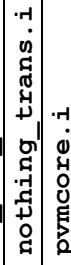 & 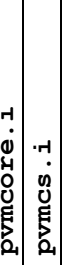 & + & 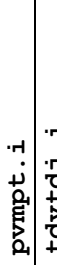 & 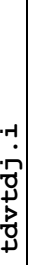 \\
\hline & 表 & $\#$ & 44 & \begin{tabular}{l|l}
45 & 4 \\
4
\end{tabular} & \begin{tabular}{ll|l}
46 & 4 \\
\end{tabular} & 748 & 49 & $5 0 \longdiv { 5 }$ & \begin{tabular}{l|l|l}
51 & 52 \\
\end{tabular} & 253 & 5455 & 556 & $5 7 \longdiv { 5 8 }$ & 859 & \begin{tabular}{l|l|l}
60 & 61 \\
\end{tabular} & \begin{tabular}{l|l|}
1 & 62 \\
\end{tabular} & \begin{tabular}{l|l}
636 \\
\end{tabular} & \begin{tabular}{l|l}
64 & 6
\end{tabular} & 65 \\
\hline Tables & & & & & & & & & & & & & & & & & & & \\
\hline POWER & $\mathrm{X}$ & $\mathrm{X}$ & & & & & & & & & & & & & & & & & \\
\hline Temperature & $X$ & $\mathrm{X}$ & & & $\mathrm{I}$ & $\mathrm{M}$ & & & & & & & & & & $\mathrm{M}$ & & & \\
\hline HTRNRATE & $\mathrm{X}$ & $\mathrm{X}$ & & & & & & & & & & & & & & $\mathrm{M}$ & & & \\
\hline HTC-T & $\mathrm{X}$ & $\mathrm{X}$ & & & & & & & & & & & & & & & & & \\
\hline HTC-TEMP * & & & & & & & & & & & & & & & & & & & \\
\hline REAC-T & $\mathrm{X}$ & $\mathrm{X}$ & & & $\mathrm{M}$ & $\mathrm{M}$ & & & & & $\mathrm{M}$ & $\mathrm{M}$ & & & & $\mathrm{M}$ & & $\mathrm{M}$ & \\
\hline NORMAREA & $\mathrm{X}$ & $\mathrm{X}$ & & & & & & & & & & & & & & & & & \\
\hline NORMVOL & $\mathrm{X}$ & $\mathrm{X}$ & & & & & & & & & & & & & & & & & \\
\hline Equation Solvers & & & & & & & & & & & & & & & & & & & \\
\hline \begin{tabular}{|l|} 
BPLU \\
\end{tabular} & $\mathrm{X}$ & $\mathrm{X}$ & $\mathrm{M}$ & $\mathrm{M}$ & \begin{tabular}{l|l}
$\mathrm{M}$ & $\mathrm{I}$ \\
\end{tabular} & $\mathrm{M}$ & $\mathrm{M}$ & \begin{tabular}{|l|l}
$\mathrm{M}$ & $\mathrm{I}$ \\
\end{tabular} & \begin{tabular}{l|l}
$\mathrm{M}$ & $\mathrm{M}$ \\
\end{tabular} & $\mathrm{M}$ & \begin{tabular}{|l|l|}
$\mathrm{M}$ & $\mathrm{M}$ \\
\end{tabular} & 1 $\mathrm{M}$ & \begin{tabular}{|l|l}
$\mathrm{M}$ & $\mathrm{N}$ \\
\end{tabular} & $\mathrm{M}$ & \begin{tabular}{l|l}
$\mathrm{M}$ & $\mathrm{N}$ \\
\end{tabular} & \begin{tabular}{l|l}
$\mathrm{M}$ & $\mathrm{M}$ \\
\end{tabular} & $\mathrm{M}$ & $\mathrm{M}$ & $\mathrm{M}$ \\
\hline MA18 (35) & $\mathrm{X}$ & $\mathrm{X}$ & & & & & & & & & & & & & & & & & \\
\hline PGMRES (34) & $\mathrm{X}$ & $\mathrm{X}$ & & & & & & & & & 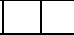 & & & & & & & & \\
\hline LSOR & $\mathrm{X}$ & $\mathrm{X}$ & & & $\mathrm{M}$ & & & & & & $\mathrm{M}$ & 1. $\mathrm{M}$ & & & & & & & \\
\hline Krylov & $X$ & $\mathrm{X}$ & & & & & & & & & & & & & & & & & \\
\hline Timestep options & & & & & & & & & & & & & & & & & & & \\
\hline Steady-state & $\mathrm{X}$ & $\mathrm{X}$ & & & & & & & & & & & & & & & & & \\
\hline Semi-implicit & $\mathrm{X}$ & $\mathrm{X}$ & & & $\mathrm{I}$ & $\mathrm{M}$ & & & & & & & $\mathrm{N}$ & & & $\mathrm{M}$ & & & \\
\hline Nearly-implicit & $\mathrm{X}$ & $\mathrm{X}$ & $\mathrm{M}$ & $\mathrm{M}$ & $\mathrm{M}$ & $\mathrm{M}$ & $\mathrm{M}$ & \begin{tabular}{|l|l}
$\mathrm{M}$ & $\mathrm{I}$ \\
\end{tabular} & \begin{tabular}{l|l}
$\mathrm{M}$ & $\mathrm{M}$ \\
\end{tabular} & $1 \mid \mathrm{M}$ & \begin{tabular}{|l|l|}
$M$ & $M$ \\
\end{tabular} & $\mathrm{M}$ & $\mathrm{M}$ & $\mathrm{M}$ & $\mathrm{M}$ & $\mathrm{M}$ & $\mathrm{M}$ & $\begin{array}{ll}\mathrm{M} \\
\end{array}$ & $\mathrm{M}$ \\
\hline Hydro-heat explicit & $\mathrm{x}$ & $\mathrm{X}$ & & & & & & & & & & & & & & & & & \\
\hline Hydro-heat implicit & $\mathrm{X}$ & $\mathrm{X}$ & & & & & & & & & & & & & & & & & \\
\hline Kinetics timestep & & & & & & & & & & & & & & & & & & & \\
\hline Card 1 options & & & & & & & & & & & & & & & & & & & \\
\hline 11 Supercritical & $\mathrm{X}$ & $\mathrm{X}$ & & & & & & & & & & & & & & & & & \\
\hline $15 \Delta \mathrm{t}_{\text {Courant }}$ & $\mathrm{X}$ & $\mathrm{X}$ & & & & & & & & & & & & & & & & & \\
\hline 23 Godunov & $\mathrm{X}$ & $\mathrm{X}$ & & & & & & & & & & & & & & & & & \\
\hline 27 MULTID testing & $\mathrm{X}$ & $\mathrm{X}$ & & & & & & & & & & & & & & & & & \\
\hline $\begin{array}{c}41 \mathrm{~K}-\text { loss energy } \\
\text { dissipation }\end{array}$ & $\mathrm{X}$ & $\mathrm{X}$ & & & & & & & & & & & & & & & & & \\
\hline 50 No flip flop & $\mathrm{X}$ & $\mathrm{X}$ & $\mathrm{M}$ & $\mathrm{M}$ & \begin{tabular}{l|l}
$\mathrm{M}$ & $\mathrm{I}$ \\
\end{tabular} & $\mathrm{M}$ & & & $\mathrm{M}$ & $1 \mid \mathrm{M}$ & \begin{tabular}{|l|l}
$\mathrm{M}$ & $\mathrm{M}$ \\
\end{tabular} & \begin{tabular}{l|l}
$\mathrm{M}$ & $\mathrm{M}$ \\
\end{tabular} & & & & $\mathrm{M}$ & $\mathrm{M}$ & $\mathrm{M}$ & \\
\hline 51 No water packing & $\mathrm{X}$ & $\mathrm{X}$ & & & & & & & & & & & & & & & & & \\
\hline 54 Void truncation & $\mathrm{X}$ & $\mathrm{X}$ & & & & & & & & & & & & & & & & & \\
\hline 55 Annular mist & $\mathrm{X}$ & $\mathrm{X}$ & & & & & & & & & & & & & & & & & \\
\hline Appendix K & & & & & & & & & & & & & & & & & & & \\
\hline Decay heat & $\mathrm{X}$ & $\mathrm{X}$ & & & & & & & & & & & & & & & & & \\
\hline Metal water reaction & $\mathrm{X}$ & $\mathrm{X}$ & & & & & & & & & & & & & & & & & \\
\hline Critical flow & $\mathrm{X}$ & $\mathrm{X}$ & & & & & & & & & & & & & & & & & \\
\hline CHF & $\mathrm{X}$ & $\mathrm{X}$ & & & & & & & & & & & & & & & & & \\
\hline Post-CHF heat transfe & $\mathrm{X}$ & & & & & & & & & & & & & & & & & & \\
\hline
\end{tabular}




\subsection{Verification Directory and Makefiles}

The Test suite is organized into a verification directory, "verify," with subdirectories of tests. The running of the tests is controlled by Makefiles. There are 6

The main Verify directory contains a single subdirectory for each test case listed at the top of the Features-Decks Matrix. It also contains the principle Makefile, its include files, the template Makefile, set_Makefile, for each of the subdirectories, directories for utility scripts. Within the subdirectories reside the input files for Category 1 and 2 testing, namely the original input deck and a restart deck. There is no Category 3 (or Category 4) input file; Category 3 (and 4) decks are generated from Category 1 decks via scripts. Initially, the only other files that may be present are APT Plot script files.

The new cases that perform coupling mode testing required new directory structure and script programming.

The PVM cases have a collection of at least 5 input decks. If the ABC problem is being run, the types and names of the decks can be:

1. PVM-Executive input deck, ABCx.i

2. Parent base input deck, ABCp.i

3. Parent restart input deck, ABCp.r.i

4. Child base input deck, ABCc.i

5. Child restart input deck, ABCc.r.i

The kind of coupling determines the non-Executive names, which is indicated by the final letter of the deck name. For example: parent-child ( $\mathrm{p}$ and $\mathrm{c}$ as above), client-server ( $\mathrm{c}$ and $\mathrm{s}$ ), and leader-follower (1 and $\mathrm{f}$ ).

The Makefiles had to be upgraded to run both RELAP5-3D standalone and coupled modes. The Make.inp direction files had to include new keywords. The main Makefile had to include options to run both modes separately and individually, individual categories (null, restart, backup) within a mode, and even to perform all tests. The set_Makefile that links to each test directory had to expand similarly. It was modified to leave the printed-output file in the directory for debugging purposes until 'clobbered.'

The Makefile also has targets for comparing restart and backup runs as explained in Sections 4 and 5 . It produces files in the MACHNAME directory named NOTREST and NOTBACK which list the names of the input tests that failed each kind of testing. The Makefile allows the Category 1, 2, and 3 tests to be run separately or all three at once. When testing succeeds, the Makefile gives the following messages:

- For null testing: 'verified'.

- For restart testing: 'Successful Restart Tests'.

- For backup testing: 'Successful Backup Tests'.

For failed tests, the corresponding directory will contain a file of differences created by the Linux "diff" function. For restart differences, the file has extension "vdif" and for backup differences, the extension is "b_dif." These files are useful for debugging purposes. 


\section{FIXING VERIFICATION TESTING}

The initial implementation revealed errors in both restart and backup for RELAP5-3D running in standalone mode. Some user problems were resolved before this project began; however, many remained and more were uncovered during the project. Comparison of verification files from coupled runs revealed new issues relating to PVM communication. Even the programming of the testing method itself proved errant, the placement of the verification backup call allowed some backup errors to go undetected and had to be moved from inside subroutine HYDRO to just after it.

Section 4.1 covers restart testing. Section 4.2 covers backup testing. Section 4.3 covers issues with the overall testing process. 


\subsection{Restart Resolutions}

Most differences in the restart cases had the same root cause, inaccuracy in the last bit of the timestep or a cumulative time on restart. A few resulted from a variable missing from the restart file. Addition of coupled cases to the test suite revealed inaccuracy in edit times calculated by paired processes, including the explicit exchange time between processes.

Differences in the final bit of the cumulative time variable caused many restart problems to differ very slightly at startup. The time for the restart problem was taken directly from the timecard and its floating point representation was as exact as possible. The corresponding time on the base run was calculated after many time steps and sometimes its floating point representation differed from the restart timecard value in the final bit. This caused some problems to drift apart but had no effect on many others.

Many solutions were considered. One that recalibrates cumulative time at every minor or major edit, restart or plot file write, and explicit exchange using quadruple precision to convert between the underlying integer time and floating point time was proposed and implemented. When implemented in the DTSTEP routines of both RELAP5-3D and the PVM Executive program, it eliminated all differences that resulted from mismatched cumulative times in coupled processes.

Additional solutions include: resetting the cumulative time to the restart time only when restarts are written and keeping a permanent quadruple precision variable for the cumulative and copy it into the double precision variable for use in the rest of the code.

For coupling cases that differed because of issues with edit times, the same concept provides the solution. All edit time conversions between integer and real were promoted to quadruple precision, just as was done for cumulative time. This resolved most issues for hydrodynamic time in coupled calculations.

A similar issue was discovered for heat transfer time in coupled mode. Heat transfer time has its own cumulative time and time-step variables that can be independent of the hydrodynamic time. Again, calculating the heat transfer cumulative time in quadruple precision resolved the issue.

$* * *$

It is noted here for future use, that keeping permanent copies of cumulative and exchange times results in more accurate timekeeping. It reduces temporal error in transients that use extreme numbers of advancements. It may become necessary, even for the timestep variable, in complex applications. If quadruple precision variables are kept, the code may still use the double precision quantities outside the timestep subroutines.

$* * *$

A few issues remained. Improving the way time variables were initialized solved a few issues. Some issues resulted from a variable needed after restart being absent from the restart file. Adding it to both the restart read and write routines solved those issues. An example is the decay heat mode variable. In a few cases, variables were read correctly but were overwritten during input processing by calculations that should only be performed when the hydrodynamic system actually changes despite the fact that the system had not changed. Most of these relate to cards the input manual states should not be included in restart decks, such as 100, 115, 119, and 120-129 cards. The subroutines that read these, RNONCN and RMFLDS have been modified to write a message and set the fail flag so that the problem will not run if one of these is present on restart.

At the end of the project, all restart issues are resolved. 


\subsection{Backup Resolutions}

If water packing ${ }^{4-1}$, flow reversal ${ }^{4-2}$, or a noncondensable appears ${ }^{4-3}$ in a volume or junction, a better solution is possible if the system of equations is modified to account for the condition in the control volume or junction associated with it ${ }^{4-4,4-5}$. Therefore, the code backs up to the beginning of the timestep, rebuilds the equations with adjustments for the backup condition, and solves the new system. A time-step backup requires the values in data to match the values at the end of the previous timestep. Therefore, old-time variables record these values at the end of each timestep.

Backup issues related to these old-time variables. The differences, between base case and runs that force an artificial backup on successful advancements, arose from four primary causes:

1. An old time variable did not exist

2. An old time variable did not receive its updated value at the end of the previous timestep

3. The old time variable was backed up in the wrong place

4. The old time was not used to restore the new time variable when backup was invoked.

Ideally, all transfers of data between current-time and backup copies occur in subroutine MOVER, either to store backup copies after an advancement or to restore data into current-time variables due to a backup. Unfortunately, MOVER is not the correct place for every transfer. Special cases had to be resolved by storing or restoring elsewhere.

For some variables, such as DFRONT, it is necessary to have not just one backup copy, but two. This is because intermediate calculations can change the value of the first backup before the actual backup takes place.

Just as with restart differences, coupling provided special backup issues. The primary issue was:

5. The PVM transferred data was not stored in old time variables after it was received.

This resulted in the code using values from before the PVM data transfer which caused differences.

All of the required backup issues have been tracked down and solved. These cases involve standalone RELAP5-3D, not coupled calculations. 


\subsection{Testing Process Issues}

Two primary issues for testing are the decision point in the flow logic where backup determination is made, and the problem of an artificial backup causing the code to perform an extra real backup that is not otherwise performed in the base case.

\subsubsection{Backup Decision Location and Timing}

The initial implementation of backup testing left several issues hidden because the decision point for backup determination was misplaced. Subroutine VERFBACKUP was moved just after the velocity calculating subroutines, VFINL and VIMPLT. This placement prevented detection of some backup issues, such as DFRONT as mentioned in Section 4.2. Moreover, a protection clause was added to allow backup testing only after the first advancement was completed and subroutine MOVER had copied new time values into the old time variables.

Both changes were made to eliminate backup comparisons that seemed to make no sense. For example, it makes no sense to try to compare new and old time values before old time values are recorded, hence the change to only begin backup comparison on the second successful advancement, after old time values are initialized by the first call to MOVER. In fact, after coupled cases were added, it became clear that some backup copies were not initialized until the second advancement in the leaderfollower couplings, and so the protective clause for VERFBACKUP was changed to NCOUNT $>2$.

However, the code does perform backups on the first advancement in some cases; Edward's Pipe is a notable example. Since backups do occur during the first advancement, it is important to detect failures to properly initialize old time variables during that advancement.

To account for the issues described above the call to VERFBACKUP was moved to immediately after the call to HYDRO, though it can be equivalently placed just before the return from HYDRO. The situation with NCOUNT was reduced to three cases, NCOUNT $>2$, NCOUNT $>1$, and NCOUNT $>0$. Since NCOUNT starts at 1 , the third case is actually unnecessary and can be removed as a protective clause altogether. These three situations were resolved in the order listed above. All of these issues fell into the 5 categories of issues identified in Section 4.2. However, the implementation of NCOUNT $>0$ revealed serious issues.

The code initializes a great many state properties at I-LEVEL through subroutine ISTATE. The subroutine that calculates those state properties in the transient, STATEP, though it uses mathematically equivalent forms, produces different values due to finite precision arithmetic. Tracking down each of these differences and resolving them was deemed beyond the scope and funding of the project, though a valuable future endeavor.

One means to resolve the differences is to call STATEP during I-LEVEL. However, this results in code failures; there is a reason ISTATE was written in the first place. Another solution is to call MOVER which calls STATEP immediately before the transient begins. This worked successfully after a few small changes. Calling MOVER early also initializes the old-time variables as is needed for backups whent NCOUNT equals 1.

At this point, all issues involving the location and timing of the backup decision have been resolved.

\subsubsection{Artificial Backup Effect}

When a true backup occurs, the code sets logical flags and then backs up. When the system of equations is built, the logical flags are always checked first and indicate how to modify the system. The flags are reset to false after the hydrodynamic calculation is deemed successful.

However, when an artificial backup occurs after a flow reversal backup, the logical flags are also reset. In flow regions with multiple hydrodynamic systems, the systems are solved independently of each 
other. What if a velocity flip-flop occurs in a second system after the original one has been rebuilt, succeeded, and followed by an artificial backup? In that case, the flags are reset in the system that originally had a backup, but then are set for the other. This causes the code to take another backup, one that the base case will not take. The solutions will diverge from that advancement forward.

This divergence does not detect an actual code problem causing the difference, but in essence creates an artificial divergence. It is a testing issue, not a code issue.

One solution is to store the logic flags before an artificial backup and restore them after the call to MOVER in DTSTEP when the advancement is deemed successful. Another solution is to recognize that this is a testing issue and not even allow an artificial backup on an advancement that has a real backup.

The former method seeks to force an artificial backup after each successful backup. Under current code logic, this does not work because the code is limited to three backups before cutting the timestep. A sequence of real-artificial-real backups makes three, so the third cannot be followed by an artificial backup. To resolve this, either artificial backups must not be counted, or the limit must be increased.

The alternate method does not force artificial backups after real ones and therefore does not enforce the "artificial backup after each successful backup" rule. Is it possible that some backup error might go undetected with this limitation of artificial backups? The artificial backup following a flow reversal would occur immediately afterwards on the next timestep, if the next advancement initially succeeds just as it did in the base case.

Currently, the former method of saving the old-time logic flags has been implemented without any change to the number of backups before cutting the time step in half.

\subsubsection{Remaining Issues}

The following are items that were not resolved during this task but do relate to verifying RELAP5-3D calculations and the correctness of verification testing. These have varying levels of importance.

1. Resolve the artificial backup effect of Section 4.3.2.

2. Resolve the PGMRES solver differences. On the first timestep of a restart or backup of the BORONM test case, a difference in the last bit of the right hand side occurs. This results in persistent differences.

3. Change the calculations in ISTATE and STATEP to produce identical results.

4. Resolve the differences in reduction counts occur in a few verification test cases. Since these are output-only variables and not primaries, they have been ignored.

5. Program an algorithm for coupled problem backup testing. Item 1 is an artifact of testing that has more possible resolutions than the ones listed above; it requires a decision at some future time. Item 2 is handled by recommending that PGMRES not be used for now. Item 3 was worked round by the early call to MOVER. Item 4 has no bearing on calculations and can be ignored safely for now. Item 5 will become important, but is not part of the workscope.

\subsection{Conclusion}

The restart/backup task has been completed and the code modifications included in RELAP5-3D Version 4.3.1. With the exception of PGMRES, all verification test cases run with no differences in the verification files. The PGMRES and reduction count differences have been recorded as user problems in the electronic ticket system for future resolution.

All the updates for fixing issues with restart and backup verification have been transmitted to the customer. The customer has installed them and reported that their code now verifies properly on all the test cases of the verification test suite. 


\subsection{References}

4-1 The RELAP5-3D Code Development Team, "RELAP5-3D Code Manual Volume I: Code Structure, System Models and Solution Methods," INL-EXT-98-00834-V1, Revision 4.0, Section 8.2, p 8-4, June, 2012.

4-2 The RELAP5-3D Code Development Team, "RELAP5-3D Code Manual Volume I: Code Structure, System Models and Solution Methods," INL-EXT-98-00834-V1, Revision 4.0, Section 8.2, pp. 8-3 to 8-4, June, 2012.

4-3 The RELAP5-3D Code Development Team, "RELAP5-3D Code Manual Volume I: Code Structure, System Models and Solution Methods," INL-EXT-98-00834-V1, Revision 4.0, Section 3.4, pp. 3-271 to 3-274, June, 2012.

4-4 G. L. Mesina, "RELAP5-3D Restart and Backup Verification Testing,” INL-EXT-13-29568, September, 2013.

4-5 G. L. Mesina, D. L. Aumiller, F. X. Buschman, "Automated, Highly Accurate Verification of RELAP5-3D," ICONE22-31153, Proceedings of the 22nd International Conference on Nuclear Engineering, Prague, Czech Republic, July 7-11, 2014. 